\title{
BACK TO BUSINESS AND (RE)EMPLOYING WORKERS? LABOR MARKET ACTIVITY DURING STATE COVID-19 REOPENINGS
}

\author{
Wei Cheng \\ Patrick Carlin \\ Joanna Carroll \\ Sumedha Gupta \\ Felipe Lozano Rojas \\ Laura Montenovo \\ Thuy D. Nguyen \\ Ian M. Schmutte \\ Olga Scrivner \\ Kosali I. Simon \\ Coady Wing \\ Bruce Weinberg \\ Working Paper 27419 \\ http://www.nber.org/papers/w27419 \\ NATIONAL BUREAU OF ECONOMIC RESEARCH \\ 1050 Massachusetts Avenue \\ Cambridge, MA 02138 \\ June 2020
}

Weinberg gratefully acknowledges support from UL1 TR002733 and R24 HD058484.The views expressed herein are those of the authors and do not necessarily reflect the views of the National Bureau of Economic Research.

At least one co-author has disclosed a financial relationship of potential relevance for this research. Further information is available online at http://www.nber.org/papers/w27419.ack

NBER working papers are circulated for discussion and comment purposes. They have not been peer-reviewed or been subject to the review by the NBER Board of Directors that accompanies official NBER publications.

(C) 2020 by Wei Cheng, Patrick Carlin, Joanna Carroll, Sumedha Gupta, Felipe Lozano Rojas, Laura Montenovo, Thuy D. Nguyen, Ian M. Schmutte, Olga Scrivner, Kosali I. Simon, Coady Wing, and Bruce Weinberg. All rights reserved. Short sections of text, not to exceed two paragraphs, may be quoted without explicit permission provided that full credit, including (C) notice, is given to the source. 
Back to Business and (Re)employing Workers? Labor Market Activity During State COVID-19

Reopenings

Wei Cheng, Patrick Carlin, Joanna Carroll, Sumedha Gupta, Felipe Lozano Rojas, Laura Montenovo, Thuy D. Nguyen, Ian M. Schmutte, Olga Scrivner, Kosali I. Simon, Coady Wing, and Bruce

Weinberg

NBER Working Paper No. 27419

June 2020, Revised July 2020

JEL No. I0,J0

\section{$\underline{\text { ABSTRACT }}$}

In the early phases of the COVID-19 epidemic labor markets exhibited considerable churn, which we relate to three primary findings. First, reopening policies generated asymmetrically large increases in reemployment of those out of work, compared to modest decreases in job loss among those employed. Second, most people who were reemployed appear to have returned to their previous employers, but the rate of reemployment decreases with time since job loss. Lastly, the groups that had the highest unemployment rates in April also tended to have the lowest reemployment rates, potentially making churn harmful to people and groups with more and/or longer job losses. Taken together, these estimates suggest that employment relationships are durable in the short run, but raise concerns that employment gains requiring new employment matches may not be as rapid and may be particularly slow for hard-hit groups including Hispanic and Black workers, youngest and oldest workers, and women.

Wei Cheng

School of Business

East China University of

Science and Technology

130 Meilong Rd, XuHui

Shanghai, China 200037

chengwei@ecust.edu.cn

Patrick Carlin

Indiana University

patcarli@iu.edu

Joanna Carroll

Indiana University

joamcarr@iu.edu
Sumedha Gupta

Department of Economics

Indiana University-Purdue

University Indianapolis

425 University Blvd.

Indianapolis, IN 46202

sugupta@iupui.edu

Felipe Lozano Rojas

Indiana University $2451 \mathrm{E}$.

10th Street Bloomington,

IN 47408

flozanor@indiana.edu

Laura Montenovo Indiana

University 2451 E. 10th

Street Bloomington, IN

474081monten@iu.edu 
Thuy D. Nguyen

Indiana University

Bloomington, IN 47401

thdnguye@indiana.edu

Ian M. Schmutte

Terry College of Business

University of Georgia

Athens, GA 30602

schmutte@uga.edu

Olga Scrivner

Indiana University

obscrivn@indiana.edu

Kosali I. Simon

O'Neill School of Public

and Environmental Affairs

Indiana University

1315 East Tenth Street

Bloomington, IN 47405-1701

and NBER

simonkos@indiana.edu

Coady Wing

Indiana University

1315 E 10th St

Bloomington, IN 47401

cwing@indiana.edu

Bruce Weinberg

Ohio State University

Department of Economics

410 Arps Hall

1945 North High Street

Columbus, OH 43210

and NBER

weinberg.27@osu.edu 


\section{Introduction}

The May 2020 Employment Situation Summary showed that non-farm payroll employment rose by 2.5 million shortly after many states lifted their stay-at-home mandates and allowed certain non-essential businesses to reopen in a gradual manner (U.S. Bureau of Labor Statistics, 2020a). While small relative to the massive decline in employment that preceded it (there were 9.4 million initial unemployment claims in March and 18.95 million in April), the substantial increase in employment is a welcome relief. Yet, the May report was a surprise for most labor economists because the initial unemployment insurance claims data in the weeks leading up to the May employment report did not seem to suggest a rebound.

In this paper, we study the dynamics of job loss and reemployment during the initial reopening phase of the US COVID-19 epidemic using a range of high-frequency data on employment and unemployment as well as longitudinally linked data from the Current Population Survey (CPS). Our work is organized around three main questions. First, how important were state reopening policies in the initial return to employment and how did movements out of employment respond compared to movements into employment? Second, what can be learned about employment dynamics, especially reemployment in previous jobs, from reopenings and, what implications do those insights have for the durability and rate of reemployment (baring or at least after further closures)? Lastly, who was actually reemployed in May, what factors seemed to drive reemployment, and do patterns in reemployment appear to accentuate or attenuate disparities in employment across groups?

A primary finding of our work, which underlies our answers to these questions, is that there has been substantial churn in labor markets during the COVID-19 epidemic and that job loss and reemployment have responded asymmetrically to reopenings. While this basic understanding may not be surprising given prior research in labor economics, it seems thus far to be under-documented in the COVID-19 labor literature. We make these points using initial unemployment claims to measure gross flows into unemployment, continuing claims to measure the stock of claims, and ending claims to measure the gross flows out of unemployment. ${ }^{1}$ While rough, these estimates imply that reemployment rates were substantial even relatively early in the epidemic. Many hundreds of thousands of workers were reemployed each week in April, largely by their previous employers, which is not surprising given media discussions of the high costs employers face in retraining workers (Shumsky and Broughton, 2020). Moreover, even as people return to work, substantial numbers of workers continue to lose jobs. Flowing

\footnotetext{
${ }^{1}$ After making attempts to account for denied claims, we show that delays in claims, while increasing and personally costly are, on average, relatively modest.
} 
from this starting point, we show that reemployment probabilities were fairly responsive to reopenings, but that job loss probabilities were fairly unresponsive.

We start by using high-frequency data to assess the importance of state reopening policies on their economies. Specifically, we apply event study designs to daily data on work-related mobility from cell devices, unemployment-related internet search activity, and weekly data on internet job postings. Work-related mobility shows clear increases in levels and/or trends around reopening announcements. At the same time, reopenings appear to have induced little, if any, reduction in unemployment-related internet searches. Given that gross flows into unemployment remain historically unprecedented, state reopenings are not primary determinants of flows out of work.

Longitudinal data from the CPS and job posting data from Burning Glass Technologies strongly suggest that most of the increase in employment came from people who returned to an existing employment relationship. Specifically, reopenings were associated with only a modest increase in job postings. Moreover, longitudinally-linked CPS data show that most reemployed workers remain in the same occupation and industry as their previous job, suggesting that they returned to their previous employer. CPS data also suggest that many people who were unemployed-on-layoff in April 2020 were misclassified as employed-but-absent from work.

Given that most rehiring in the May CPS appears to be by the original employers, at least initially, recovery from the COVID-19 pandemic will likely depend on the original employers' ability to resume business. Our longitudinally-linked CPS data provide evidence that reemployment probabilities decline with the length of time unemployed. While this decline in reemployment hazards is consistent with a causal effect of duration dependence, it is also consistent with time / duration varying heterogeneity. During the COVID-19 epidemic, we believe that the scope for worker-side time / duration varying heterogeneity is relatively small. ${ }^{2}$ This finding suggests that the connection between employees and employers may well decline the longer they are apart. If so, that bodes poorly for the rate of reemployment in later phases of the recovery.

Lastly, we study who was actually reemployed in May. For a wide range of demographic groups, we relate the probability of reemployment in May to the probability of being unemployed in April in our longitudinally-linked CPS data. Along most observable dimensions other than education, the probability of reemployment in May is lower for groups who had

\footnotetext{
${ }^{2}$ Intuitively, workers did not stop working gradually over a long period with substantial scope for selection. Rather, businesses closed quite rapidly with many workers left out of work. On the other hand, employers who closed earliest may reopen more slowly (e.g. if they are in more exposed industries like hospitality), which would constitute a form of employer-side time / duration-varying heterogeneity.
} 
the highest unemployment in April. Thus, men, non-Hispanic whites, and the prime-aged were all less likely to be unemployed in April and, conditional on being unemployed in April, more likely to be reemployed in May. The same appears to be true to some extent when the workforce is divided by industry or occupation, with some of the hardest hit industries and occupations having the lowest reemployment probabilities. By contrast, highly-educated workers are less likely to be unemployed in April, but do not have a higher subsequent reemployment probability.

The negative relationship between reemployment probabilities and unemployment probabilities suggest that the churn we highlight, including repeated declines and upticks in employment, may well generate increasingly large disparities across groups. Put differently, if reemployment probabilities were relatively constant across groups or even higher for the groups with the highest unemployment rates, then returns to work would not accentuate or would actually attenuate disparities across groups in employment. Given that reemployment rates are frequently lower for groups who experienced the greatest reductions in employment, the return to work will accentuate disparities even further. If this patterns is maintained as labor markets experience churn during repeated closings and reopenings, disparities in recovery will be greatly exacerbated in this recession, following patterns seen in earlier recessions (Schanzenbach et al., 2017).

\section{Related Research}

The social science literature on COVID-19 and employment is evolving rapidly, thus, our literature review will likely be incomplete. However, this paper relates to several themes that have started to emerge in other articles. One line of work examines the way in which the epidemic and social distancing policy responses have affected labor market outcomes overall, although none we are aware of have used matched CPS data through May to study reopenings. Lozano-Rojas et al. (2020) show that the historically unprecedented increase in initial unemployment claims in March 2020 was largely across the board, occurring in all states regardless of local epidemiological conditions or policy responses. Baek et al. (2020) come to a broadly similar conclusion with UI records, examining a longer time period. Campello et al. (2020) provide evidence on labor demand using job postings data from Linkup, although not as a function of state policy. They find that job postings decline about 2 weeks before the large rise in UI claims. They also find that job postings by small firms decline much more than job postings by large firms, that job postings decline more for high- than low-skilled jobs, and that job postings drop more in concentrated labor markets. Kahn et al. (2020) show 
a large drop in job vacancy postings in the second half of March. They report that, by early April, there were $30 \%$ fewer job postings than at the beginning of the year. These declines also largely happened across states, regardless of state policies or infection rates. While their primary focus is on expectations and consumer spending, Coibin et al. (2020) use custom data to show that lockdowns are related to worse labor markets, controlling for COVID-19 cases. Similar work is underway to analyze the economic effects of the epidemic in other countries (Adams-Prassl et al., 2020; Dasgupta and Murali, 2020; Rothwell and Van Drie, 2020).

Recent papers study the effects of closures, but not reopenings, on particular subpopulations, often highlighting the role of job characteristics. We note that reopenings and closures are likely to be asymmetric given the differences between terminating or freezing employment relationships and bringing workers back to work. Montenovo et al. (2020) and Fairlie et al. (2020) study early labor market outcomes during the epidemic using CPS data from April 2020. They find high rates of recent unemployment that vary across groups, with particularly high job losses among younger workers, Hispanic workers, workers in non-essential industries, workers in jobs that are harder to perform remotely, and workers in jobs that require more face-to-face contact. Furthermore, they show a hump-shaped pattern in job losses by education. Dingel and Neiman (2020) and Mongey and Weinberg (2020) also study high work-from-home occupations. Leibovici et al. (2020) take a similar approach to measure occupations with high interpersonal contact. Alon et al. (2020) find that the COVID-19 epidemic may have a larger economic effect on women than men, unlike in a "regular" recession. A number of researchers have sought to provide results at a higher frequency than the CPS. Blick and Blandin (2020) provide information on a number of demographic groups using data from the Real-Time Population Survey, which is conducted every other week. Cajner et al. (2020) use the payroll microdata from Automatic Data Processing, Inc (commonly known as ADP). Aaronson et al. (2020) build a forecasting model that uses Google searching activity for unemployment-related terms to predict weekly unemployment insurance claims, and find that unemployment insurance claims and Google searches for unemployment insurance both peak prior to stay-at-home orders. In this spirit, we draw on UI claims data as well as cell device mobility to workplaces in order to provide high-frequency information to augment our CPS analyses. However, note that Coibion et al. (2020) use data from an early-April household survey and finds that unemployment rate may greatly exceed unemployment insurance claims.

Another line of work examines the effects of state and local social distancing policies on measures of mobility and interaction. Using cell signal data, Gupta et al. (2020) and Fairlie (2020) document a massive, nationwide decline in multiple measures of mobility outside the 
home. They also find evidence that early and information-focused state policies did lead to larger reductions in mobility. These reductions in time spent outside the home suggest that many people are experiencing work disruptions, and that those who can work remotely may be more able to maintain employment during the crisis.

This work relates as well to the large literature on the importance of worker-firm relationships and the consequences of disrupting productive job matches. For workers, sudden job losses have substantial negative long-term consequences on earnings (Jacobson et al., 1993), particularly during recessions (Davis and von Wachter, 2011; Farber, 2017). Recent evidence suggests earnings losses from job disruption are associated with loss of match-specific capital, which takes time to build (Lachowska et al., 2018). The loss of productive workers is also very costly to firms (Jäger and Heining, 2016) and they must go to great expense in replacing them (Friebel et al., 2019). At the macro level, the process of forming and dissolving good job matches depends on costly search, and contributes both to the depth and dynamics of recession (Lise and Robin, 2017). While typical recessions have a cleansing effect by targeting the least productive firms and jobs, the effects of the COVID-19 pandemic are largely unrelated to pre-pandemic productivity. Stabilization policies have therefore operated in part to preserve employment relationships both in the United States (Chetty et al., 2020) and abroad (Bennedsen et al., 2020).

\section{Data}

\subsection{State Activity Closure Data}

We use data on state social distancing (closure) policies that were previously reported in Gupta et al. (2020). Basic information about the timing of state policy actions was originally collected by Washington University researchers (Fullman et al., 2020) and Boston University researchers (Raifman et al., 2020).

\subsection{Reopening Policy Data}

We use the timing of initial reopenings by state that were previously reported in Nguyen et al. (2020) (see Figure 1). We collected and coded data on state reopening policies, starting with the New York Times descriptions of each state's reopening policies and gathering additional information on the reopening schedules for each state through internet searches and states' guidance. South Carolina became the first state to reopen on April 20, 2020. All states took steps to reopen by June 1. We also tracked the date of official 
announcements by governors regarding their detailed reopening plans. A typical state announces their reopening plan about 4 days prior to the effective date of reopening (median). ${ }^{3}$ This implementation period varies by state (the gap between orange and blue dots in Figure 1). We provide the information we have compiled from various sources on GitHub (https://github.com/nguyendieuthuy/ReOpeningPlans).

\section{$3.3 \quad \mathrm{O}^{*} \mathrm{Net}$}

The 2019 Occupational Information Network (O*Net) contains a module on characteristics of the Work Context, which reports summary measures of the tasks used in 968 (2010 SOC) occupations (O*NET National Center for O*NET Development (2020)). The data are gathered through surveys asking workers how often they perform particular tasks. This module is assembled by $\mathrm{O}^{*} \mathrm{NET}$ from survey questions asking workers about their need for face-to-face interaction with clients, customers, and co-workers. Other questions assess the reliance of each job on activities that could be performed remotely (i.e. from a worker's home). These measures are typically provided on a 1-5 scale, where 1 indicates that a task is performed rarely or is not important to the job, and 5 indicates that the task is performed regularly or is important to the job. Following Montenovo et al. (2020), we use indices of for face-to-face interactions and potential for remote work. We standardized these indices for the analysis. Montenovo et al. (2020) include more details on how these indices are built.

\subsection{Homeland Security Data on Essential Work}

The U.S. Department of Homeland Security (DHS) issued guidance about critical infrastructure workers during the COVID-19 epidemic ${ }^{4}$. The DHS guidance outlines 14 categories that are defined as essential critical infrastructure sectors. We follow Blau et al. (2020)'s definition of essential industries, which matches the text descriptions to the NAICS 2017 four-digit industry classification from the U.S. Census Bureau ${ }^{5}$, and to the CPS industry classification system. From the 287 industry categories at the four-digit level, 194 are identified as essential; these essential industries are found in 17 out of 20 NAICS sectors.

\footnotetext{
${ }^{3}$ There is one exception to this-in Illinois, the governor released a phased plan of reopenings on May 5 , several days after the initial reopening of certain outdoor activities actually took place.

${ }^{4}$ The list of critical infrastructure jobs is available at: https://www.cisa.gov/

${ }^{5}$ North American Industry Classification System. Available at https://www.census.gov/
} 


\subsection{Weekly Unemployment Insurance Claims}

We also study the number of UI claims in each U.S. state and Washington, DC, from the first week of 2019 to the week ending in May 30, 2020. We utilize the Department of Labor Weekly Claims Data (ETA 539), which provides state-by-week counts of the number of initial and continuing UI claims; continuing claims captures all claims in a state/week that were initiated and certified prior to that week. If this happens, a claimant who met monetary requirements may still be denied (Anderson and Meyer, 2000; Vroman et al., 2017). We note that a single person can initiate and be paid multiple claims for different jobs. Thus, the claims should not be interpreted as representing unique individuals. We focus on the number of new UI claims per covered worker, using the number of covered workers as of January 2020 as a fixed denominator to avoid changes in rates driven by changes in covered employment. Additionally, we construct weekly outflows from UI with these data, allowing us to estimate net flows into the program, the difference between the number of claims entering and exiting the program each week, assuming a $20 \%$ denial rate. $^{6}$

\subsection{Monthly Unemployment Insurance First Payment Delays}

To assess the timing of UI benefit provision we use the monthly first payment activity data (ETA 5159) and the monthly payment delay data (ETA 9050). While the ETA 5159 data provides a monthly count of total first payments made, the ETA 9050 provides the monthly count of those first payments that experienced a delay. These delays in first payments are measured as the time difference between the first week a claimant is eligible to receive a payment and the date the payment was actually made (mailed, deposited, etc.). These delayed payments are grouped by the number of weeks $(1-11+)$ payments were delayed, with counts reported by the month in which the first payment was made (as opposed to when the claim was initiated). Given the attention paid to delays in the provision of unemployment insurance benefits, we use these data points to construct monthly measures of the amount of delay for first payments nationally and for states individually. Due to the certification process outlined above it is expected that all claims will experience some delay between the filing of the claim and the payment. ${ }^{7}$

\footnotetext{
${ }^{6}$ A detailed description of how denial rates are calculated can be found in the results section of this paper.

${ }^{7}$ It is important to note that all but five states have a one week waiting period. In these states the first week after an initial claim is filed is not considered compensable. However, all but nine states with wait weeks have waived the wait requirement during the pandemic. (NCSL, 2020)
} 


\subsection{Work-Related Mobility Data}

We extract work-related mobility from two cell signal aggregators: Google mobility and Safegraph. In the Google data, we use a day-by-state-level index of activity detected in work locations. In the Safegraph data, we focus on a state-by-day measure of the fraction of devices detected at locations that Safegraph has defined as likely to be the device owner's work location. The advantage of these data is that they are available at the daily level and provide a way for us to investigate whether employment followed a different trend in states with early social distancing policies, a challenge in the CPS data given its monthly schedule. However, cell phone mobility data have not been widely used in labor economics research and their properties are not well understood. We view them as a proxy for time spent at a person's typical work location. These measures will not capture remote work, which has become more common during the epidemic. It is also likely that the quality of these measures could deteriorate when overall unemployment rates and job disruptions are high. After a protracted period of working from home or unemployment, many people will no longer have a meaningful, distinct workplace to serve as a reference point for work-related cell phone mobility measures. In the CPS, our concept of employment does not depend on whether it is done physically at a work location or at the same physical location as earlier. Thus, we view the mobility data as supplementary to the CPS data.

\subsection{Google Trends Search Data}

We obtain information on day-by-state internet search behavior through the Google Trends API, which allows us to follow internet search queries across different terms, topics, and geographies, in a way that allows comparisons across time and place ${ }^{8}$. We pull data from queries related to unemployment and unemployment benefits as suggested in the Google Trends webpage and previously reported in Gupta et al. (2020) (see Figure 5). The final series represents the total number of searches across all search terms in a state per 10 million searches.

\subsection{Job Vacancy Data}

We use Burning Glass Technologies (BGT) data covering virtually all online job postings by US employers. BGT collects, cleans, and parses online job advertisements from approximately

\footnotetext{
${ }^{8}$ We access these data using the apiclient.discovery package for Python and its function getTimelinesForHealth. For a thorough explanation of the different information available with Google Trends see www.medium.com
} 
40,000 job boards and websites (Deming and Kahn, 2018; Scrivner et al., 2020). We obtain weekly online job postings, by state, between June 22, 2019 and June 10, 2020. The job advertisements data is stratified by industry and state in this study. The measure is the number of weekly job postings per 100,000 state population.

\subsection{Current Population Survey}

We use data from the Basic Monthly CPS from January 2015 to May 2020, including all individuals aged 21 and above. There are between 76,000 and 97,000 observations per month. These surveys ask respondents about their labor market activities during a reference week that includes the 12th of the month (U.S. Census Bureau, 2019). Our primary measure of employment status is the share of the population that the CPS codes as being employed and at work. This measure excludes people who have a job but were temporarily absent ${ }^{9}$. Lozano-Rojas et al. (2020); Bogage (2020); Borden (2020) highlight the importance of properly coding people who are employed-but-absent for measuring employment status during the COVID-19 epidemic. ${ }^{10}$ Given the importance that absence from work has gained during the epidemic, we also consider the outcome "Absent - Employed," which only includes those workers classified as absent from work but still employed during the Basic Monthly CPS.

In order to investigate factors associated with people's probability of reemployment, we create a longitudinal sample by matching respondents in the CPS from April to May in 2020. The matching scheme consists of two steps: first, we match individuals with identical household identifier and individual line number. Second, we delete matches where genders differ or ages differ by three or more years, as recommended by IPUMS. For comparison, we also created two-period panels from March to April 2020 and from April to May in 2019. The matched samples cover 51,366 individuals from April to May 2020, 53,148 individuals from March to April 2020 and 61,581 individuals from April to May 2019.

\footnotetext{
${ }^{9}$ The CPS defines as "absent from job" all workers who were "temporarily absent from their regular jobs because of illness, vacation, bad weather, labor dispute, or various personal reasons, whether or not they were paid for the time off" (U.S. Census Bureau, 2019).

${ }^{10}$ First, some employers released workers intending to rehire them. Second, some workers may have requested leave from their schedule to provide dependent care or to care for a sick household member. Third, there was a misclassification problem during the data collection of the March and April 2020 CPS. Specifically, the BLS instructed surveyors to code those out of work due to the epidemic as recently laid off or unemployed, but U.S. Bureau of Labor Statistics (2020d), U.S. Bureau of Labor Statistics (2020b), U.S. Bureau of Labor Statistics (2020c) explain that surveyors appeared to code at least some of them in the employed-but-absent category. These factors contribute to a massive increase in the share of workers coded as "employed-but-absent" from work between February and May. In our sample, the employed-but-absent share rose by almost $150 \%$ from February to April, 2020, and by 82\% from February to May, 2020.
} 


\section{Econometric Methods}

We conduct four broad empirical analyses. Our first analysis applies straight-forward stockand-flow accounting methods to initial claims and continuing unemployment insurance claims to document gross and net flows into and out of the unemployment insurance system. In doing so, we discuss delays in claim certification and denial rates. Second, we examine the connection between state reopening policies and labor markets using high frequency measures, including cell device measures of work-related physical mobility, Google trends data on unemploymentrelated internet search activity, and job postings. The cell device and Google search data provide information at the day-by-state level. Our job postings data are at the week-by-state level. We use an event study model to analyze the immediate local changes in work-related mobility, unemployment-related Google searches around reopening events, and job postings. When measuring timing of reopening policies, in order to capture potential announcement effects and preparation for reopening, we focus on the later of the announcement date and four days before the reopening itself (the median time from announcement to initial reopening is four days), which we refer to as the truncated announcement date.

This second set of results provides relatively high-frequency measures of labor-marketrelated activity, and they allow us to assess pre-trends and anticipation effects in considerable detail. However, these data are all aggregated and do not allow us to track individuals over time. We turn to the CPS to study more conventional measures of labor market performance. In the third analysis, we use monthly CPS data to estimate the effects of state reopening policies in a generalized difference-in-difference framework. Lastly, we construct a longitudinal CPS sample by matching individuals across months to study employment transitions at the individual level between April and May 2020.

\subsection{High-Frequency Data: Work-Related Mobility, Google Trends, and Job Postings}

We conduct event study analyses using high-frequency data including work-related mobility, Google trend searches and job postings. We use variation across states in the timing of reopening policies, defining the time of the policy shock by a truncated announcement date. We fit event study regression models with the following structure:

$$
y_{s t}=\sum_{a=-l}^{-2} \alpha_{P a} 1\left(t=R_{s}+a\right)+\sum_{b=0}^{u} \beta_{P b} 1\left(t=R_{s}+b\right)+\theta_{s}+\gamma_{t}+\epsilon_{s t}
$$


In the model, $R_{s}$ represents the truncated calendar day (week) of state $s$ 's announcement of a reopening policy. We set lower $(l)$ and upper limits $(u)$ for the event time coefficients following the availability of periods. For the daily analyses of mobility data and Google Trends data, we allow for a window of 20 days before and after policy. In the weekly analyses for job postings we follow up to 4 weeks prior to the policy change and 3 weeks after. $\theta_{s}$ is a set of state fixed effects, which are meant to capture fixed differences in the level of outcomes across states that are stable over the study period. $\gamma_{t}$ is a set of daily or weekly time fixed effects, which capture trends in the outcome that are common across all states. $\epsilon_{s t}$ is a residual error term. The $\alpha_{P a}$ and $\beta_{P b}$ are event study coefficients that trace out deviations from the common trends that states experience in the days leading up to and following reopening policies. The reference period in the event study is one period before the adoption of the reopening policy.

Meanwhile, we also estimated a linearized version of the event studies to better capture the change in intercepts and change in linear trends before and after the policy. Let $D_{s t}=t-R_{s}{ }^{11}$, so it represents number of days since (or before) the truncated announcement of reopening for state $s$ in time $t$. The regression is specified as follows.

$$
y_{s t}=c_{B}+\rho_{B} D_{s t}+c_{A} \text { After }_{s t}+\rho_{A} D_{s t} \times \text { After }_{s t}+\theta_{s}+\gamma_{t}+\epsilon_{s t}
$$

where After $_{s t}=1$ if $t \geq R_{s}$. Therefore, $c_{A}$ and $\rho_{A}$ capture the changes in the intercept and linear time trend respectively after the policy compared to pre-policy levels.

\subsection{Monthly CPS Analysis}

We use the January 2019 to May 2020 waves of the monthly basic CPS data to estimate the effects of the state reopening on labor market outcomes using a generalized version of a difference-in-difference model. Specifically, let $t^{*}=$ May 12, 2020 be the focal date of the May CPS. Then Reopen $_{s}=t^{*}-R_{s}$ is the number of days since a state's truncated announcement on reopening as of the May CPS focal date. Finally, let Maymt be an indicator variable equal to 1 if the observation is from the May 2020 CPS and set to 0 otherwise. We fit a DID regression model that examines the effect of reopenings:

$$
y_{i s m t}=\delta_{1}\left(\text { Reopen }_{s} \times \text { May }_{m t}\right)+X_{i s m t} \beta+\theta_{s}+\gamma_{m t}+\epsilon_{i s m t} .
$$

\footnotetext{
${ }^{11}$ Within the estimation time window, we replace values less than -20 by -20 , and also replace values greater than 20 by 20 .
} 
The main effects of the Reopen s and Maymt are absorbed in the state fixed effects and month $\times$ year fixed effects. $\delta_{1}$ measures the extent to which the May 2020 labor market changes were larger among states that had been "open" for an additional day.

\subsection{Longitudinal CPS Analysis of Employment Transitions}

Using the longitudinally linked CPS sample, we study factors related to an individual's likelihood of reemployment as well as likelihood of job loss in May 2020. To adjust for potential seasonality in job flows between April and May, we also constructed a longitudinal sample for April-May 2019. Combining the 2019 and 2020 April-May samples, we let $t=2019,2020$ index the two years of April-May data, and let $Y 20_{i s t}=1(t=2020)$ be a dummy variable indicating that the person is observed in the 2020 sample rather than the 2019 sample. We fit the following model to the pooled sample:

$$
\begin{aligned}
y_{i s t}= & E_{i s t} \lambda_{1}+d_{i s t} \alpha_{1}+J_{i s t} \rho_{1}+\left(Y 20_{i s t} \times \text { Reopen }_{s}\right) \delta \\
& +\left(Y 20_{i s t} \times E_{i s t}\right) \lambda_{2}+\left(Y 20_{i s t} \times d_{i s t}\right) \alpha_{2}+\left(Y 20_{i s t} \times J_{i s t}\right) \rho_{2} \\
& +X_{i s t} \beta+\theta_{s}+\delta_{t}+\epsilon_{i s t}, t=2019,2020
\end{aligned}
$$

The first outcome variable $y_{i s}$ we study is a binary indicator of whether individual $i$ in state $s$ is reemployed in May focusing on individuals who were not working in the April. This includes people whose employment status is coded as "employed-absent", "unemployed-on layoff" and "unemployed-looking". Individual $i$ 's April employment status is represented by a set of dummy variables $E_{i s} . d_{i s}$ represents duration of the person's unemployment spell in weeks as reported in April. $J_{i s}$ contains features of individual $i$ 's previous job, including whether it involved work in an essential industry, the amount of face-to-face contact, and availability of remote work. ${ }^{12}$ We also control for two-digit NAICS industry fixed effects and two-digit SOC occupation fixed effects. $X_{i s}$ is a vector of individual demographic and education characteristics. All these explanatory variables are interacted with the year dummy variable to account for potential differential effects in 2020 versus 2019. To consider the impact of state reopening policies, we include number of days since reopening as of the May CPS focal day (denoted by Reopen ${ }_{s}$ ) interacted with year in the regression. State fixed effects $\theta_{s}$ and year fixed effects $\delta_{t}$ are also controlled for.

Using the same regression framework, the second outcome variable $y_{i s}$ we examine is a

\footnotetext{
${ }^{12}$ See Montenovo et al. (2020) for a discussion of our measures of essential industries, face-to-face contact, and remote work capacity. These are measured at the industry or occupation level and are identified from variation within the industry and occupation cells reflected by our dummy variables.
} 
binary indicator of whether individual $i$ in state $s$ loses a job in May focusing on individuals who are employed and at work in April. These two analyses allow us to look at both job inflows and outflows to understand current job activities better. Furthermore, we also investigate factors influencing individual's earnings and hours worked conditional on being employed and at work in May. We can thus compare earnings and hours worked for people who have been employed in both April and May and people who transition from out-working in April to working in May.

\section{Results}

\subsection{Flow of Unemployment Insurance Claims}

We start by investigating the trends in weekly initial and continuing unemployment insurance (UI) claims by state, around the time of reopening policy. This analysis frames the rest of our discussion and highlights the substantial churn in labor markets. While many researchers have studied initial claims, continuing claims have received considerably less attention. Figure 2 graphs the weekly rates of initial and continuing unemployment insurance claims calculated as the number of initial/continuing claims divided by the size of the labor force. The thick black line shows the "smoothed" 7 day moving average of the national estimates, while the grey lines show the individual state estimates. The grey lines turn red after each state's truncated date of initial reopening announcement, which we henceforth refer to as reopening announcements for brevity. The initial claims rate peaks in early April and then declines steadily. The declines start well before any state's initial reopening announcements. Continuing claims peak around mid-May and then decline slightly. This peak appears to come right around the first group of state initial reopening announcements.

We next address gross flows out of unemployment insurance, which involve understanding delays in unemployment insurance benefits as well as claims denial rates. There has been extensive media attention paid to delays in processing unemployment insurance benefits. The delay represents the time between the first compensable weeks of benefits and the date the payment is made (mailed, deposited, etc.); the payment will cover the first compensable week of the established benefit year. ${ }^{13}$ Panel A of Figure ?? reports the estimated average number of weeks UI first payments are delayed, by month. Even in March and April, during the

\footnotetext{
${ }^{13}$ To get a sense of time between filing a claim and first payment, most states impose a week's waiting period, so the first week of unemployment is not compensated. However, all but nine of these states waived this week during this current crisis, so there is only a delay in processing, and compensation paid will cover all previous weeks since filing (NCSL, 2020).
} 
beginning of the pandemic, delays in first payments are between 1 and 2 weeks. Another way to examine these is to look at the percentage of total first payments subject to a delay by the length of the delay. Panel B of Figure ?? shows that between $40 \%$ and $50 \%$ are delayed by about 1 week, while $30 \%$ to $40 \%$ are delayed by 2 to 3 weeks. Very few claims are delayed for 4 or more weeks. There is a distinct reduction in the share of claims paid in the first week in April, almost entirely offset by claims that take 2 to 3 weeks. ${ }^{14}$ While there is some increase in claims delayed 4 to 8 weeks, which can have a tremendous personal cost, this increase is relatively small. ${ }^{15}$ Based on these findings, when trying to align the initial and continuing claims in Figure 2 we assume that the majority of these claims are paid quickly and thus we do not make adjustments for payment delays.

Understanding denial rates is important for estimating flows in and out of the program. While looking at claims gives an overall sense of unemployed individuals, a substantive number of these claimants are ineligible for the program and thus never enter UI. In order to estimate denial rates we use monetary (ETA 218) and non-monetary determinations (ETA 207) data, starting from first quarter 2010 through the first quarter of 2020. Once a claim is filed it must go through a certification process in order to be paid; the amounts paid will cover the first compensable week onward. This process consists of two steps known as determinations. The first step, which all claims go through, is a monetary determination, which measures whether the claimant meets baseline wage and employment requirements for UI. The second step, which only some claims go through, is a non-monetary determination, which is typically initiated by the claimant's employer if they believe the claimant does not meet the separation requirements (i.e. that they quit their job or were fired for misconduct). Combined monetary and non-monetary claims denials create an overall denial rate for initial claims. This rate has been roughly $20 \%$ every quarter since 2015 , thus, we assume roughly $80 \%$ of all initial claims during the 2020 period we study become certified and receive payment.

Figure 4 plots national gross and net unemployment insurance claims flows as well as smoothed series. The series for gross flows that get to be actual payments at some point is simply the number of initial UI claims in thousands over time from the first week of March to the last week of May 2020, using the $20 \%$ denial rate we derived from past data. Gross flows onto UI, after accounting for denials, increased from a low level in early March to an

\footnotetext{
${ }^{14}$ The increase in the number of claims paid quickly in March may well be an artifact of data reporting. Because of the surge in claims that occurred later in March, only those claims that were processed quickly would have been paid in March.

${ }^{15}$ It should also be noted that these estimates do not give us a sense of delays in ability to file a claim, which has also been an issue of great concern during the pandemic since they cause personal hardship. Since are only able to observe claims filed, the recording of both initial and continuing claims do not reflect when the job loss occurred.
} 
unprecedented level of roughly 5 million in the first week of April. Gross flows then fell substantially and steadily until the series ends, but remain quite elevated.

The line depicting net flows shows the number of initial (non-denied) claims minus the number of ended claims in a given week. ${ }^{16}$ Positive net flows indicate that more people are entering than leaving UI. Net flows peak quite early - at the beginning of April. They display a substantial, steady downward trend throughout April. In May the raw data show volatility in the measure of net flows, but the smoothed estimates indicate the trend turning negative by early May. The April and May trends display a substantial and increasing mobility off of UI.

The difference between gross and net flows provides an estimate of outflows from unemployment insurance. While small relative to the gross flows onto unemployment insurance, gross flows exiting unemployment insurance are not negligible even in March. They grow considerably during April to roughly 1 million people per week and end the period at well over 2 million people per week.

Taken together these estimates indicate tremendous churn in the labor market with considerable and consistently growing numbers of people returning to work even as many others are losing jobs. These outflows begin long before the reopening announcements period and suggest that the increase in reemployment was not solely driven by reopenings.

\subsection{Google Search Trends for Unemployment Related Terms}

Despite the UI estimates suggesting that flows into unemployment have been trending downward since early April, claims are reported at a relatively low frequency for this recession and do not correspond 1-to-1 with unemployment. We turn here to another high-frequency signal of flows into unemployment: Google search trends for unemployment-related search terms $^{17}$. Choi and Varian (2012) show that Google searches for unemployment-related-terms queries are predictive of downstream unemployment insurance claims and Aaronson et al. (2020) apply the idea to the COVID-19 epidemic. Thus, these searches provide additional, indirect, suggestive, high-frequency information on how employment changes around state reopenings.

Figure 5 reports event study results for the change in the log of the number of searches around the announcements of state reopenings. For the specification with a complete set

\footnotetext{
${ }^{16}$ Given most claims have been recent, and the expansions of benefits, ending claims are dominated by people who are reemployed rather than timing-out of benefits.

${ }^{17}$ These search terms include unemployment, unemployment benefit, stimulus, assistance, CARES act, department of labor, and insurance claims.
} 
of time dummies for days before and after the announcements of reopening, there is little evidence of a pretrend, but after the announcement date, unemployment-related searches begin to trend down slightly. The estimates in the linear model show an approximately $3 \%$ decrease in the intercept at our reopening announcement date. Our estimates suggest that reopening policies explain only $4.6 \%$ of the decline in the number of daily unemploymentrelated searches between the week of April 13-19 and last week of May. Thus, reopenings appear to have had only a minor effect on unemployment-related searches. These estimates are consistent with the large downtrend in initial unemployment claims preceding reopenings. Along with the large continued flows into unemployment, they suggest that reopenings are unlikely to be able to stem at least the gross flows into unemployment.

\subsection{Work-Related Mobility Patterns}

The preceding analyses show that there was a substantial decline in net flows into unemployment before and around the time of reopenings, and that UI and internet search behavior declines are only very partially attributable to reopening policy. This section analyzes highfrequency data on work related mobility drawn from the locations of cell devices with an event study analysis to quantify the effects of local policy changes on work-related mobility. These measures do not allow us to distinguish gross flows into and out of employment, but provide one measure of the overall level of employment (at least in traditional physical work locations).

Figure 6 plots the event study coefficients estimating the change in workplace mobility following the state's announcement of reopenings. The left panel shows estimates for 'change in mobility in work locations' from Google Mobility data. The right panel shows estimates for changes in 'Fraction of devices at work' locations from SafeGraph data. The study window runs from April 15, 2020 to June 19, 2020. The vertical gray line indicates the truncated announcement date of reopening in the state.

The pretrends prior to the announcement dates in the Google mobility data are fairly flat, but there is a clear break in trend after the announcement date (left panel). Data from SafeGraph show a distinct downward pretrend prior to the announcement dates with a clear trend break at the announcement date and, if anything a slight uptrend afterward. While the pretrends differ across the two datasets, both show a distinct upward trend break in work-related mobility after the announcements. The share of the changes in work mobility from April 15th to June 19 that can be explained by reopenings ranges from $10 \%$ to $12 \%$. Thus, reopenings appear to have played some role, but not a primary role in increasing 
work-related mobility. One explanation for these results is that flows out of employment appear to be fairly unresponsive to reopenings while flows back into employment are more responsive. Work-related mobility combines both sources of variation.

\subsection{Burning Glass Job Postings}

Given an uptick in employment that at least broadly coincides with reopenings, we turn to data from Burning Glass Technologies (BGT) to assess the extent to which the increase in employment was associated with an increase in job postings, as an indicator of the formation of new employment relationships as opposed to the resumption of previous employment matches. The top panel of Figure 7 plots the national weekly online job postings by US employers overall between June 22, 2019 and June 10, 2020. After a precipitous decline in job postings in March 2020, there is a noticeable increase in postings in early May 2020. We observe the lowest number of job postings in May 2 - May 9 during this time period (approximately 330,000 vs. 644,000 in March 7 - March 13). Similarly, the number of job

postings in healthcare sectors declines by $80 \%$ between March 7 and May 2. The total job postings recover nationally in recent weeks $(539,000$ in June 6 - June 10). This uptick appears across most sectors.

We next turn to an event study design to assess how the timing of postings in each state relates to reopenings. Figure 7 presents the results from an event study analysis of the effects of initial reopening announcement dates using state-by-week-level data on online job vacancies between April 11 and June 10, 2020. After controlling for national trends, there may be a slight increase in job searches after reopenings. However, the change appears to be relatively limited. When viewed in conjunction with the earlier results suggesting an increase in people returning to work, this small increase in job postings indicates that the initial increase in employment likely came from people returning to previous employers. New job postings are likely to be more relevant in later phases of reemployment. If so, it may well entail a slower process of reemployment because of the time associated with job search and matching as well as firm-specific human capital accumulation.

\subsection{Monthly CPS DID Analysis}

The analyses above examine trends in employment generally, but do not examine individual trajectories or specific subgroups of the population. We use the monthly CPS for a more detailed analysis of employment categories and outcomes. Table 1 reports results on the effect of reopening policies for 6 labor outcomes - (i) employment; (ii) employed-but-absent; 
(iii) earnings among the employed; (iv) earnings in the full sample, including people with zero reported earnings; (v) hours worked among the employed; and (vi) and hours worked in the full sample, including people with 0 hours of work. The earnings analysis is limited to people in the outgoing rotation groups of the CPS sample because only these groups are asked questions about earnings. All regressions are weighted using the appropriate CPS sampling weights. ${ }^{18}$

The estimates imply that an additional day since reopening increases the probability of being employed by 0.2 percentage points. Given that the weighted average number of days since the initial announcement of reopenings in the CPS sample is around 10 days, the reopening policies increase employment rate by 2 percentage points, which accounts for $77 \%$ of the difference in employment rates between April and May 2020. The estimates also show that at the sample average of roughly 10 days, reopening reduces the probability of being employed-but-absent group by 0.07 percentage points, which is $56 \%$ of the change in the probability of being employed-but-absent between April and May.

Meanwhile, an additional day post reopening announcement is associated with 0.05 more hours worked last week overall (i.e. including zeros) and a $1 \%$ increase in overall earnings, but there are no effects conditional on being employed. This implies that the increase in earnings and hours of work are largely from due to movements along the extensive margin instead of the intensive margin.

Taken together, these results indicate that local reopenings likely played a larger role in increasing employment than suggested by our event study analyses. To some extent the difference likely arises because the event study design emphasizes sharper breaks in timing than the difference-in-difference design. But, as shown, there are large, continuing flows into unemployment and, as shown in our Google Trends analysis and unpacked further using CPS data below, these flows into unemployment are not highly responsive to reopenings. By contrast, we show below using our longitudinally linked CPS data that reemployment of people who are out of work is considerably more responsive to reopening policies.

\subsection{Longitudinal CPS Analysis}

We use the longitudinal CPS for detailed analysis on the demographics of the reemployed. The panel of graphs in Figure 8 shows the distribution of employment status in a recent month by sub-populations defined by employment status in the previous month. Panel A reports employment status shares in May 2020 by employment status in April 2020. For

\footnotetext{
${ }^{18}$ We use the earnings study weights for analysis based on the earnings outcome, and the final CPS sampling weight for all other analyses.
} 
comparison, Panels B and C show similar plots for March-April 2020, and April-May 2019. Looking at Panel A for May 2020 employment status patterns stratified by employment status in April 2020, the first column shows that people who were employed and at work in April 2020 were disproportionately employed and at work in May of 2020. At the same time, approximately $6 \%$ of those employed in April 2020 were in another employment status in May 2020, which is roughly $20 \%$ higher than the rate in 2019. This large, monthly increase in outflows from employed-at-work illustrates the increased flows out of the employed-at-work category even at a time when people are returning to work. Still the outflows are a quarter those from March to April of 2020 shown in Panel B. The second column reports estimates for people who were employed-but-absent from work in April 2020. This category, which is supposed to include people who are, for instance, on vacation, has received considerable attention in technical discussions that have spilled over into the public discourse because many people who were unemployed-on-layoff probably have been misclassified into this category. The third column reports people who were listed as unemployed-on-layoff. One would typically expect these two categories to differ substantially in terms of subsequent labor market status, with the employed-but-absent from work being very likely to return to work, as in 2019. Instead these two columns are strikingly similar in ways that do hint to some meaningful amount of misclassification. For instance, both of these groups have somewhat under a $40 \%$ probability of being employed in May of 2020. We find that the employed-but-absent in April are more likely to be listed as employed-but-absent in May rather than as unemployed-on-layoff in May while those unemployed-on-layoff in April were more likely to be listed as unemployed-on-layoff in May than employed-but-absent. However, the sum of employed-but-absent and unemployed-on-layoff in May, is close to $50 \%$ for both the employed-but-absent and unemployed-on-layoff in April. Thus, while there appears to be persistence in classification into these two categories, it seems highly likely that there is some misclassification into these two groups. The balance of the employment statuses for the employed-but-absent and unemployed-on-layoff in April is quite similar for these categories. ${ }^{19}$

The remaining columns show considerable persistence. Roughly half of the April unemployed and looking for a job remaining in that category in May and only $15 \%$ are employed. This low return rate among the unemployed looking for a job compared to the substantially higher rates among the employed-but-absent from work and unemployed-on-layoff is strong suggestive evidence that the return to work between April and May was a product of people

\footnotetext{
${ }^{19}$ Interestingly, these categories diverge considerably more from April to May than from March to April of 2020, suggesting that more of the employed-but-absent in March 2020 were actually employed-but-absent than in April.
} 
who had retained a relationship with their original employers returning to work rather than people finding new jobs. Not surprisingly, virtually all of the April retired and disabled remain in those categories in May. Roughly $70 \%$ of people not in the labor force in April remain out of the labor force in May. Taken as a whole, these estimates show that there was generally retention in work with some outflows from employment among those employed in April 2020, and resumption of work between April and May was among people who had retained relationships with their prior employers. The resumption of work is far weaker among the other groups.

We now turn to people who are newly reemployed in May 2020 and compare them to the newly reemployed in May 2019. An individual is defined as newly reemployed if in April they were classified as unemployed-on-layoff, unemployed and looking, or employed-but-absent from work, and then in May were classified as employed and at work. Figure 9 breaks down the composition of April employment status for this group in 2019 and 2020 for comparison. Panel A shows the fraction of individuals belonging to each April employment status and their reemployment probability. All categories of non-working individuals are less likely to go back to work in May 2020 versus 2019. We also see far more people on temporary layoff and far fewer people looking for a job in April 2020 compared to 2019. Panel B shows that, in May 2019, roughly 70\% of the newly reemployed had been employed-but-absent in April 2019. Just under $10 \%$ had been on layoff and roughly $20 \%$ had been looking in April of 2019. By contrast, in May 2020, roughly 40\% of the newly reemployed had been employed-but-absent in April 2020 while over 50\% were coming off layoff and less than 10\% had been looking in April 2020. Intuitively, far fewer people who were being reemployed in May of 2020 were newly hired (had been looking) than in May of 2019, and far more had an employment relationship in April of 2020 than in April of 2019. Below we use data on industry and occupation changes to assess the likelihood that they were returning to the same job as opposed to taking a new job. Presumably, the reemployment of people who had been on layoff increases relative to that of people who had been employed-but-absent between 2019 and 2020 because more of the employed-but-absent in April 2020 were effectively on layoff in 2020 than in 2019, making for a smaller return probability.

Unfortunately, the CPS does not indicate whether people who are reemployed are returning to a previous employer or have found a new job. Lacking that information, we use changes in industry and occupation as proxies for employer switches. These measures are at best proxies because people who switch employers may not switch industries and/or occupations and people who do not switch employers may switch industries and/or occupations. The latter may be more common if employers move people between establishments or across jobs 
in response to COVID-19. Moreover, even if workers do not change industries or occupations, there is reporting / coding noise in these classifications. With those caveats, Figure 10 reports the fraction of workers within different employment status categories that switched industries (Panel A) or occupations (Panel B). These results are reported for 2019 (left) and 2020 (right) for comparison. For workers who are recorded as unemployed (whether on temporary layoff or looking) in April, the industry and occupation switches are those that occurred between April and May in case they regain employment during these two months. We see that very few people who are employed (whether at work or absent) switch either industries (top panel) or occupations (bottom panel) between April and May of either 2019 (left panel) or 2020 (right panel).

The low and relatively constant rate of switching among the formerly employed-but-absent appears to contrast somewhat with many of our previous results, which suggested that in April 2020, employed-but-absent workers were more similar to those on layoff than in the past. At the same time, one explanation for this low switch rate may be that fewer people on layoff are switching industries or occupations in 2020 than in 2019. Indeed, the next columns show that fewer people who are unemployed-on-layoff switch industries and occupations when they are reemployed in 2020 than in 2019. The same pattern can also be seen for the those unemployed and looking in April, and employed in May, though their switch rate is the highest compared with the other groups. Given that the reemployed individuals in May consist mostly of people who are employed-but-absent or unemployed-on-layoff (Figure 9), these results suggest that the increase in employment in May is due to more people being rehired by their previous employers in May. It is also possible that new employers are only hiring people who are very well suited to their positions in the sense of having immediately relevant previous experience.

Figure 11 reports the probability that people who were unemployed (including on temporary layoff and looking for a job) in April are employed in May by their duration of unemployment in April. The top panel reports results for April and May 2020; the bottom panel reports results for April and May 2019. The left panel shows the share of people who are unemployed for different lengths of time in April of both years. In April 2020, the share of people unemployed for 7-8 weeks or more is low and the counts decline at higher duration of unemployment. The share of people unemployed is markedly higher for duration of 0-2 weeks, 5-6 weeks, and especially 3-4 weeks (which corresponds to the weeks of March 15 and 22). Not surprisingly, the data for 2019 are considerably more flat. The right panel reports estimates for the probability that people remain unemployed versus being reemployed in May. In 2020, there is a large monotonic decline with the duration of unemployment 
in the reemployment probability. The 2019 shows a broadly similar, but considerably less regular pattern. While this cut through the data is different from the previous one, it tells a remarkably consistent story - reemployment between April and May 2020 was substantially higher among people who had recent connections to their employers.

Next, we look at the patterns of the unemployment rate and the reemployment rate by demographic characteristics, education, occupation, and industry. The relationship between unemployment probabilities and reemployment probabilities is consequential for disparities across groups. In particular, if the groups with the highest unemployment rates have the highest reemployment rates, then disparities across groups will decline, but if the groups with the highest unemployment rates have the lowest reemployment probabilities than disparities across groups will increase. Panel A of Figure 12 reports results by educational attainment. Not surprisingly, it shows that unemployment is declining in education. However, there are only very small differences in reemployment probabilities across education levels. These findings indicate that while education is protective against unemployment, conditional on being unemployed, it is not associated with a higher reemployment probability.

Panel B reports results by age. It is clear that reemployment probabilities are greatest for people who are in their prime working years, peaking between ages 41 and 50 and decreasing monotonically for younger and older workers. This pattern follows unemployment by age, which is lowest for the 41-50 group and increases for both younger and older workers. Thus, the age groups most protected against unemployment are also most likely to become reemployed. Panel $\mathrm{C}$ reports results by gender. Women are more likely to be unemployed and have somewhat lower reemployment probabilities. Panel D reports results by race and ethnicity. Unsurprisingly, non-Hispanic whites have the lowest unemployment rate, and they also have the highest reemployment probability. Out of all four racial and ethnic groups, Asians have the lowest reemployment probability.

Panel E presents unemployment rate and reemployment probability for 22 occupation groups. Conditional on being unemployed in April, the healthcare practitioner, production, community and social services, legal, and healthcare support occupations were more likely to regain employment in May than people in other occupations. Computer and mathematical occupations had the lowest probability of reemployment among those who were not working, but that was the occupation group with the lowest unemployment rate in April. Aside from the food preparation and serving and personal care occupations, there is no obvious relationship between unemployment rates in April and reemployment in May. Yet food preparation and serving and personal care are noteworthy given their very high unemployment rates in April (of $42 \%$ and $30 \%$, respectively) and well below average reemployment probabilities in 
May. Panel F reports results for 20 industries. Construction, agriculture, and manufacturing industries had the highest probabilities of reemployment. Health care is among the largest of the industries and of particular interest in the context of the pandemic. This sector had an April unemployment rate of $9.5 \%$ and fared fourth best in reemployment probability. The arts, entertainment, and recreation and accommodation and food services had the highest April unemployment rates at 38.4\% and 37.4\% respectively. They also experienced low reemployment probabilities. Aside from these industries, the relationship between unemployment in April and reemployment in May is relatively weak.

While we find that reemployment probabilities across education groups are fairly similar despite large differences in unemployment rates, in general Figure 12 shows that most demographic and occupational groups with lower unemployment in April also have a higher chance of reemployment in May. This pattern will tends to accentuate disparities across groups and is particularly troubling given the prospect of multiple rounds of layoffs and returns to work and our finding that reemployment probabilities are highest for those who have maintained links to employers. Thus, there is the potential that while some workers will be able to return to their previous employers, others will become increasingly disconnected from employers and have to find new jobs, which is a slow process in any circumstance and likely to be particularly daunting in the current environment.

Finally, we turn to regression analysis. Table 2 reports the effect of various worker and demographic characteristics on worker's job transitions by estimating Equation (3) using the matched April-May groups in the CPS in 2019 and 2020. Columns (1)-(3) study reemployment probabilities in May for those in the labor force, but not at work in April, and Columns (4)-(6) look at likelihood of job loss in May for those employed-at-work in April. Columns (1) and (4) report estimates for 2019, columns (2) and (5) report those computed using 2020 data, and columns (3) and (6) report the difference between 2020 and 2019 coefficients.

The first three columns show that reopening policies are significant and positively related to a worker's reemployment probability, which is consistent with Table 1. For each extra day since the reopening implementation, the reemployment probability increases by 1.1 percentage points among the not-at-work individuals in April. If interpreted causally, the estimated coefficient on reopenings indicates that in the absence of state reopenings, the reemployment probability would have been 20\% in May 2020 instead of the observed 31\%. Thus, reopenings appear to have increased the reemployment rate by $53 \%$ compared with the counterfactual scenario where states had not reopened. Both years show that reemployment probabilities are highest for employed-but-absent workers followed by the unemployed-on-layoff, both groups have higher returning rates than the reference category of those unemployed and looking for 
a job. While the reemployment probabilities of the unemployed-on-layoff decline modestly between 2019 and 2020 relative to the unemployed-looking, the reemployment probabilities drop dramatically for the employed-but-absent. This finding suggests that the employed-butabsent are quantitatively different in 2020 compared to 2019. The unemployment duration shows a negative effect in both years. However, people with longer length of unemployment are even less likely to be reemployed in 2020 compared to 2019. Importantly, the coefficients on job characteristics show major changes between 2019 and 2020. Being in an essential industry or in job with remote work possibilities were insignificantly related to reemployment in 2019 but became significant in 2020. Being an essential worker is associated with a 6.1 percentage point higher probability of reemployment in 2020, and the ability to do work remotely is associated with a 4.3 percentage point higher probability of reemployment. Thus, characteristics of a job that were previously unrelated to reemployment have become important during the COVID-19 epidemic.

Columns (4)-(6) in Table 2 analyze people who are employed and working in April and study the likelihood of people transitioning to being out of work, including unemployed (looking or on layoff) as well as people who are employed-but-absent, in May. In contrast to those in Columns (1)-(3), reopening policies do not play significant roles in keeping people at work. This lends support to our argument that state reopenings encourage job inflows but have much less, if any, effect on outflows from work. These findings can help reconcile the strong employment estimates Table 1 with the weak estimates for unemployment-related searches in the event study analysis. Among the job characteristics, face-to-face contact is associated with a higher probability of job losses in 2020, but not in 2019. In terms of education levels, workers with higher education attainment (bachelors degree or graduate degree) are less likely to lose jobs, and this benefit is stronger in 2020 than 2019.

Among individual characteristics, the estimates are consistent with what are shown in Figure 12, women, and older workers (people 61 or older) are more likely to lose jobs and less likely to transition back to work. Thus, these groups are disadvantaged both in terms of job loss and job gains.

Table 3 takes weekly earnings (Columns 1-3) and weekly hours worked (Columns 4-6) for those who are employed and working in May as outcomes. As in Table 2, columns (1) and (4) report estimates for 2019, columns (2) and (5) show those in 2020, and columns (3) and (6) display the differences between 2020 and 2019 coefficients. Reopening policies are not related to earnings but are associated with greater hours worked among those working in 2020. An additional ten days of reopening is associated with an increase of 0.6 hours worked in the week before the CPS reference week. Among those working in May, those who were 
also employed in April have significantly higher earnings and hours worked than people with other employment statuses in April of both years. Workers employed in April had 20\% higher earnings in May compared to those who were unemployed and looking in April 2020. In terms of hours worked in the week before the survey, those who were employed in April work four hours more in the week before the May 2020 CPS. Thus, the reemployed workers face a wage and hours worked penalty when compared to those who kept their jobs throughout the period. Among those at work, people in essential jobs and with greater remote working possibilities have higher earnings and hours in both years, with no meaningful change between 2019 and 2020. Workers in jobs with higher Face-to-Face Index also have higher hours worked in both years, conditional on working. The other demographic variables have the expected signs.

\section{Conclusion}

The COVID-19 epidemic led to a massive and sudden reduction in economic activity in the United States and other countries. Although unemployment rates remained at very high levels, employment began to recover somewhat in May 2020. This paper examines the relationship between state reopening policies and the return to work using multiple high frequency data sources as well as more conventional data from the monthly CPS.

Unemployment insurance claims data show a tremendous amount of churn between employment and unemployment during this initial reopening phase of the epidemic. Flows out of and back into employment responded asymmetrically to state reopenings. Specifically, movements back to employment are considerably more responsive to reopening than are flows out of employment. Furthermore, the flow of workers back into employment was primarily due to workers returning to their previous employers after a temporary absence. This combined with a reemployment hazard among the unemployed that declines steadily in the duration of unemployment point to the value of strong, recent relationships to an employer.

Taken together, these results suggest that the uptick in re-employment may reflect a scenario where firms want to employ a given level of labor to operate at a given level of activity. Firms can quickly resume operating without costly search or job training because their workers were available in the sense of not having found new jobs and largely wanting to return to work. If this reflects the current labor market situation, it is likely that firms could recall most of their previous workforce into employment without high hiring costs (Friebel et al., 2019), and workers can forego costs usually borne after being displaced from a productive job match (Lachowska et al., 2018).

However, displacement costs may well mount for workers who are not called back to 
work. When we disaggregate the workforce by race and ethnicity, gender, age, industry, and occupation, but not education, groups with the highest unemployment rates in April tend to have lower reemployment rates in May. Given the churn that we identify and the potential for additional rounds of closings and reopenings, the burden of job loss may well be increasingly borne by the most disadvantaged groups. This unevenness in the recovery period is not specific to this recession. Cajner et al. (2017) and Schanzenbach et al. (2017) show that non-White employment appears more cyclical, consistent with our findings of worse employment experiences for non-White populations during this recession. The time needed to rebuild the match-specific capital lost in those jobs may contribute to prolonged recession (Lise and Robin, 2017). If the cost of labor market disruptions do continue to fall on the least advantaged, that should be accounted for in retraining and antipoverty programs intended to respond to the COVID-19 recession. 


\section{Tables and Figures}




\section{Figure 1: States' Reopening Timelines}

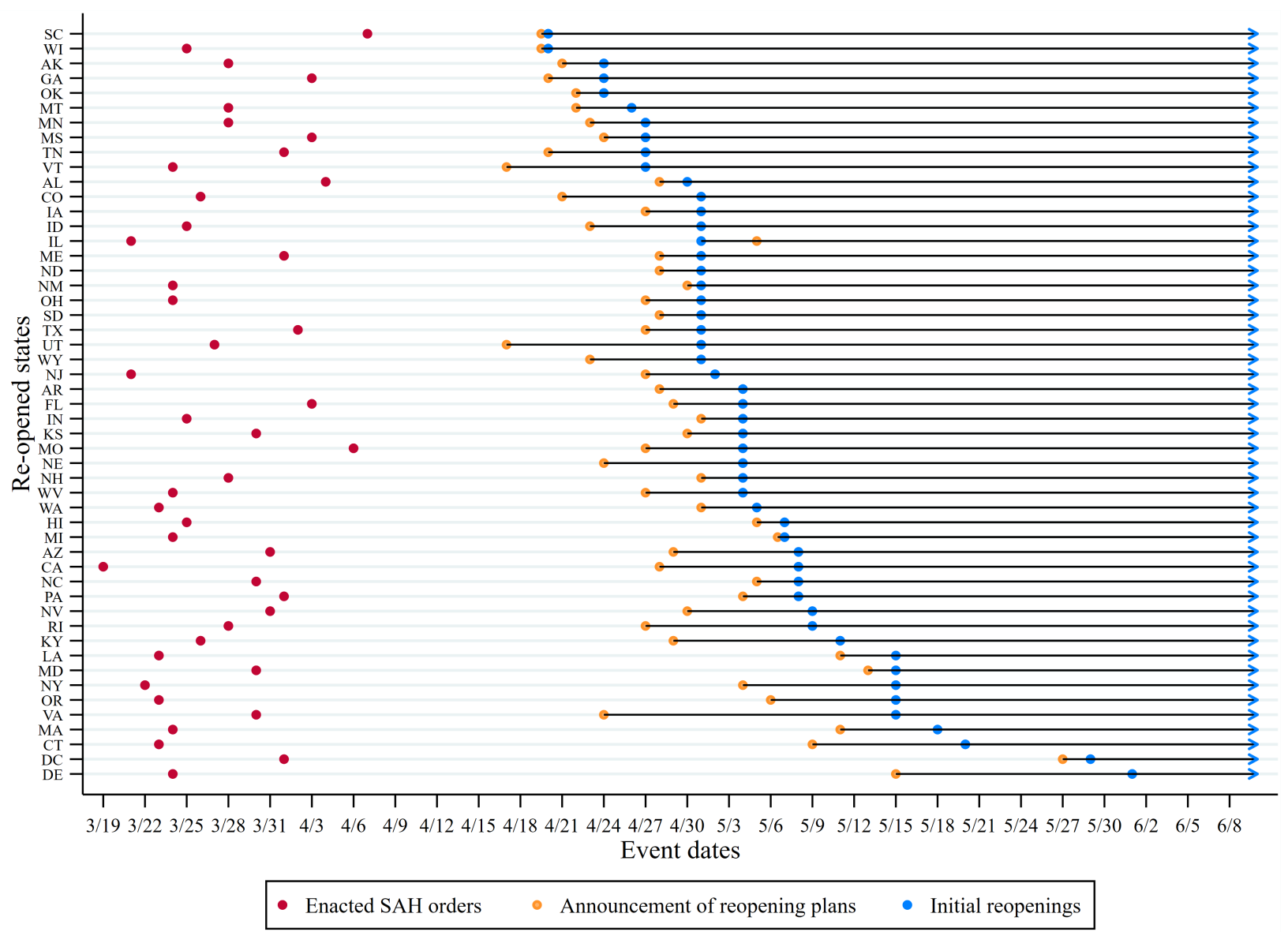

Notes: Figure shows for each state, the timeline of their SAH orders (red), official announcement of reopening plans (orange), and initial reopening (blue). The Illinois governor released a phased plan of reopenings on May 5, several days after their initial reopening on certain outdoor activities (according to the timeline of the New York Times). The timeline is updated as of June 15. We provide the details of States' reopening timelines at https://github.com/nguyendieuthuy/ReOpeningPlans. 
Figure 2: Trends in initial and continuing unemployment insurance claims.
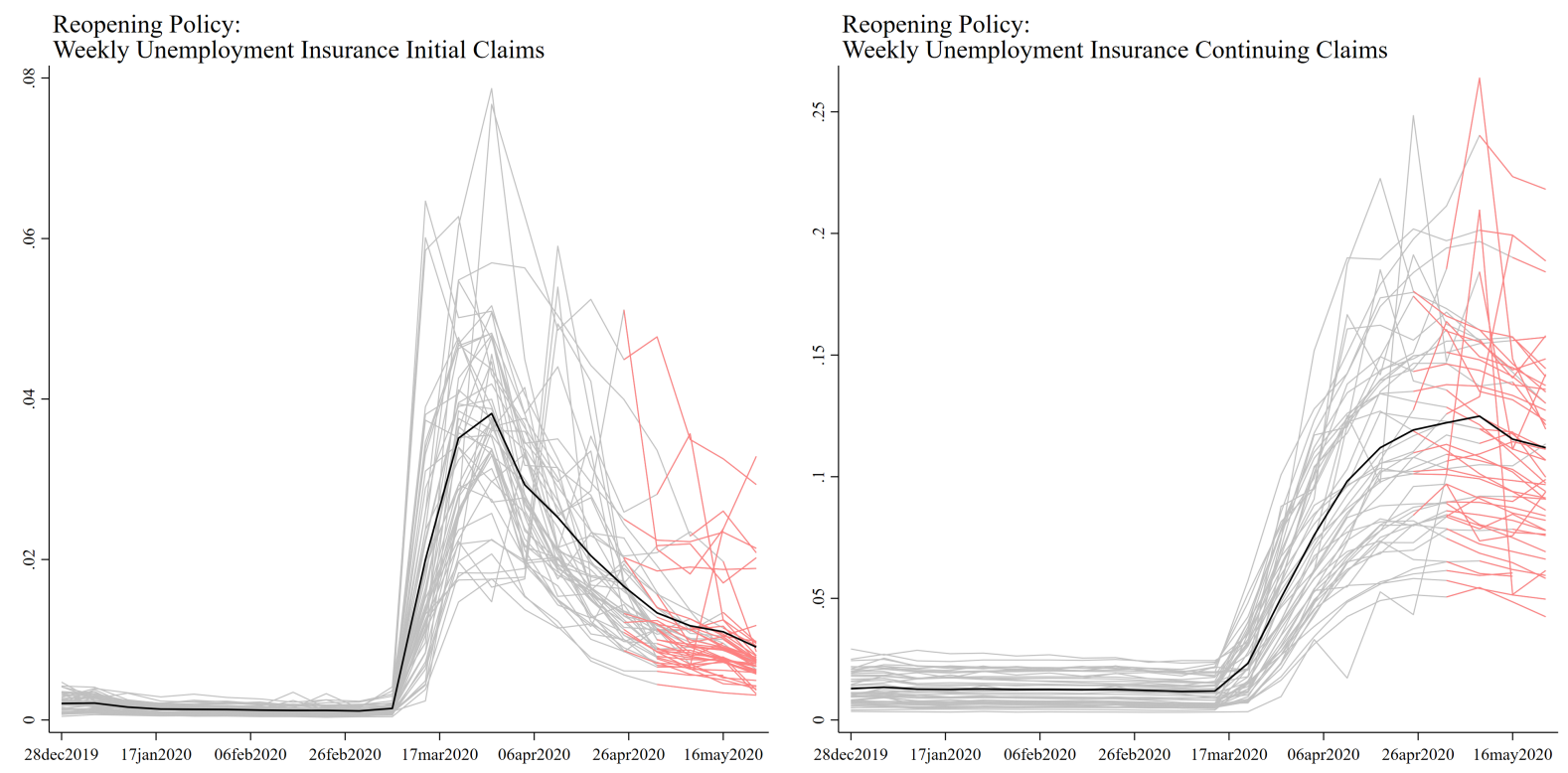

Notes: The panels present the authors' estimates of the weekly rates of initial and continuing unemployment insurance claims calculated as the number of initial/continuing claims divided by the January 2020 labor force, as estimated by the Bureau of Labor Statistics. Each line represents a state. The gray segments are for the period before the states truncated announcement date of reopening; the red segments represent periods after truncated reopening announcement. The thick black line represents a "smoothed" 7 day moving average of the states. 
Figure 3: Monthly First UI Payment Delays
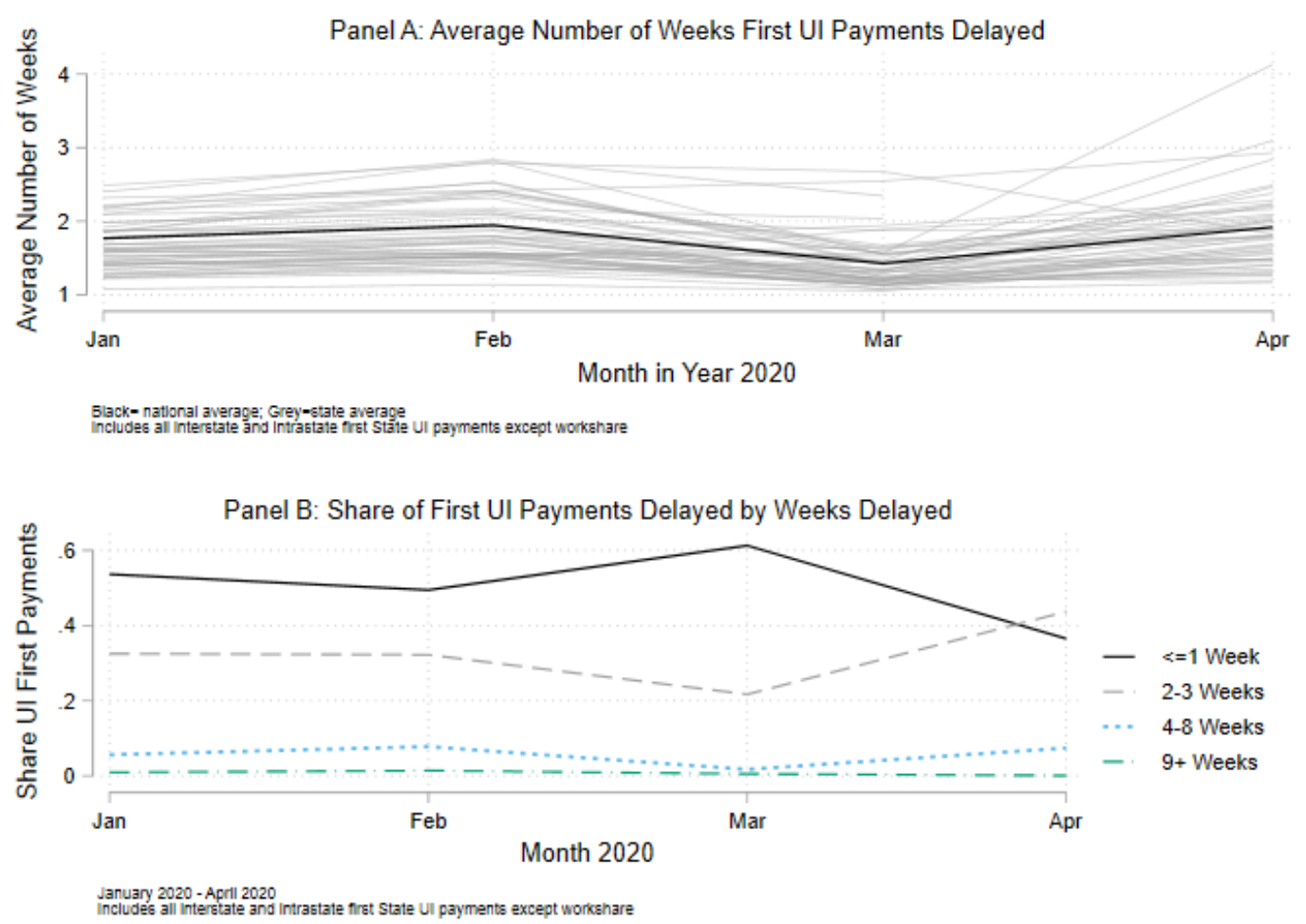

Notes: Panel A presents the authors' estimates of the average number of weeks UI first payments are delayed by month. Panel B presents the authors' estimates of the monthly share of first payments delayed by number of weeks delayed. These figures combine the monthly first payment activity data (ETA 5159) and the monthly payment lapse data (ETA 9050). Estimates in both panels include all State UI (full and partial) interstate and intrastate first payments. Workshare payments are excluded. 
Figure 4: Gross and Net Unemployment Insurance Flows

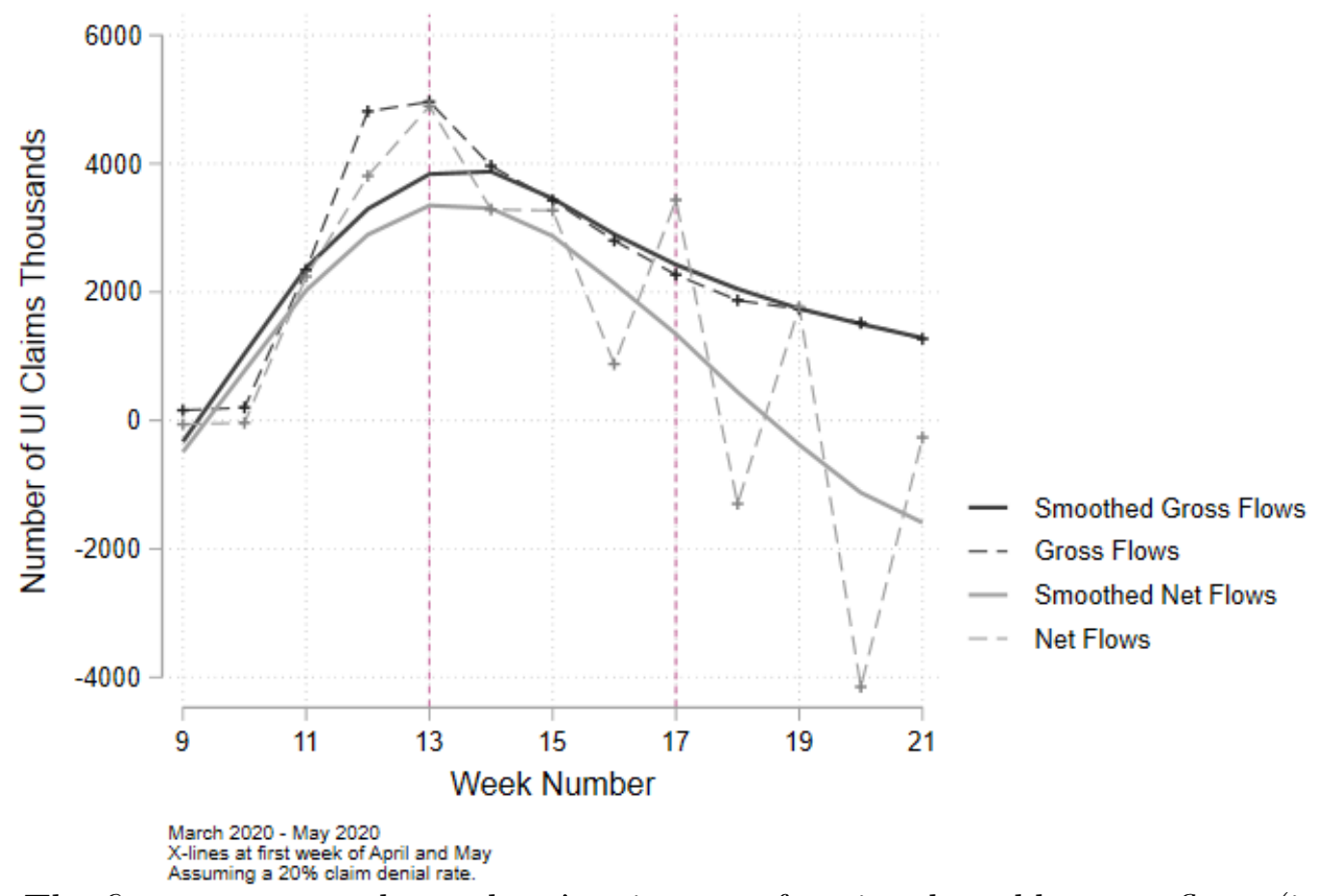

Notes: The figure presents the authors' estimates of national weekly gross flows (incoming cases) and net flows onto UI (incoming UI claims less ending UI claims) based on initial and continuing claims data each week. These estimates assume a $20 \%$ denial rate on initial claims. The difference between the two series gives the gross outflows from UI. Both raw data and smoothed series are included. Smoothing done with cross validated bandwidths. 
Figure 5: Effect of state re-openings on Google Trends unemployment-related Searches

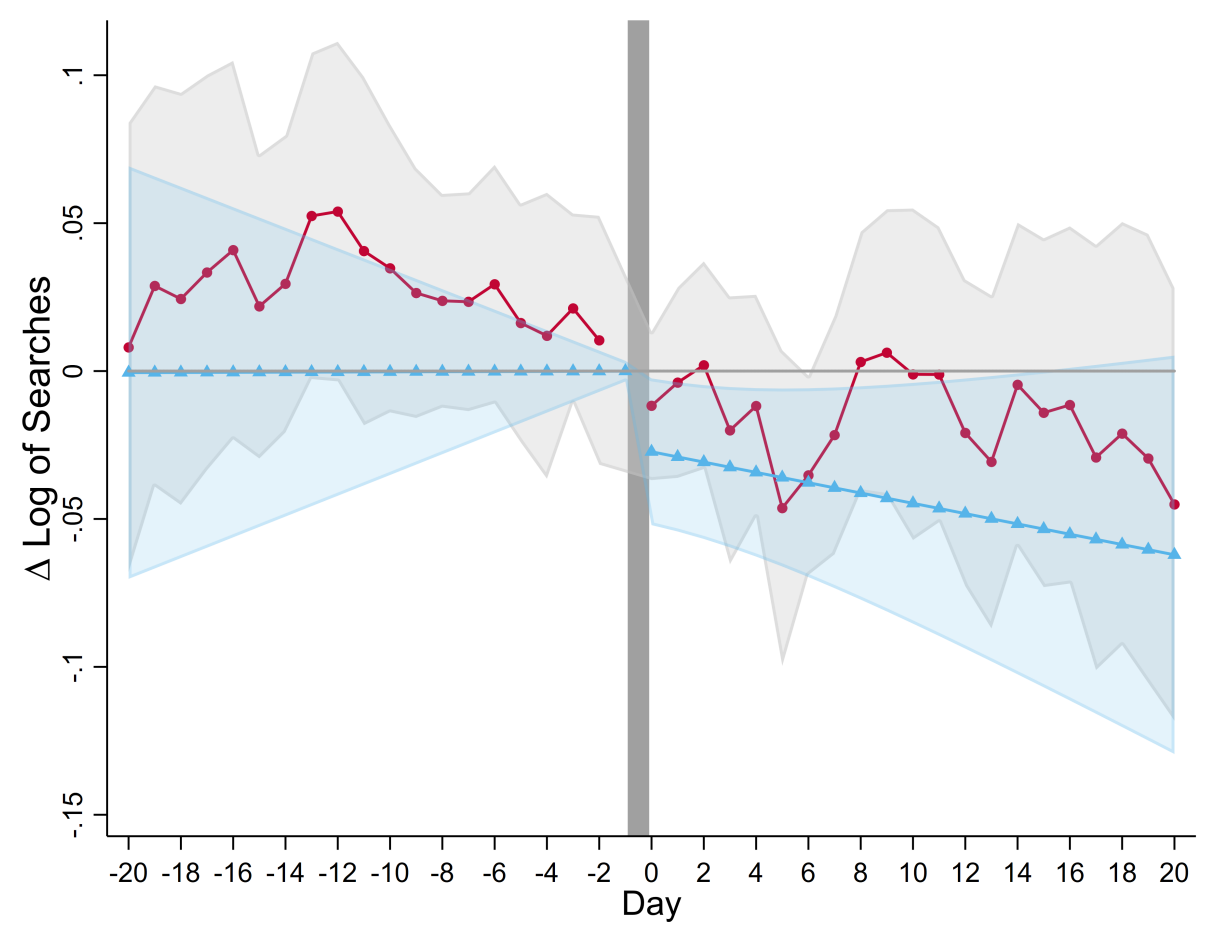

Notes: Authors' calculation based on Google Trends search data. The outcome variable is $\log$ of the number of searches for unemployment-related terms, including unemployment, unemployment benefit, stimulus, assistance, CARES act, department of labor, insurance claims. The vertical gray line represents the day before the truncated announcement date. The red series and grey shading are estimates from an event study with a set of dummy variables indicating each day. The blue series and shading are estimates from a linearized event study where linear time trends are imposed before and after policy change. Regressions control for state fixed effects and date fixed effects. The estimation window is 1 April 2020 12 June 2020. 
Figure 6: Effect of state re-openings on work related mobility. Regression Results (Coefficients and 95\% Confidence Intervals) (April 15 - June 19 2020)

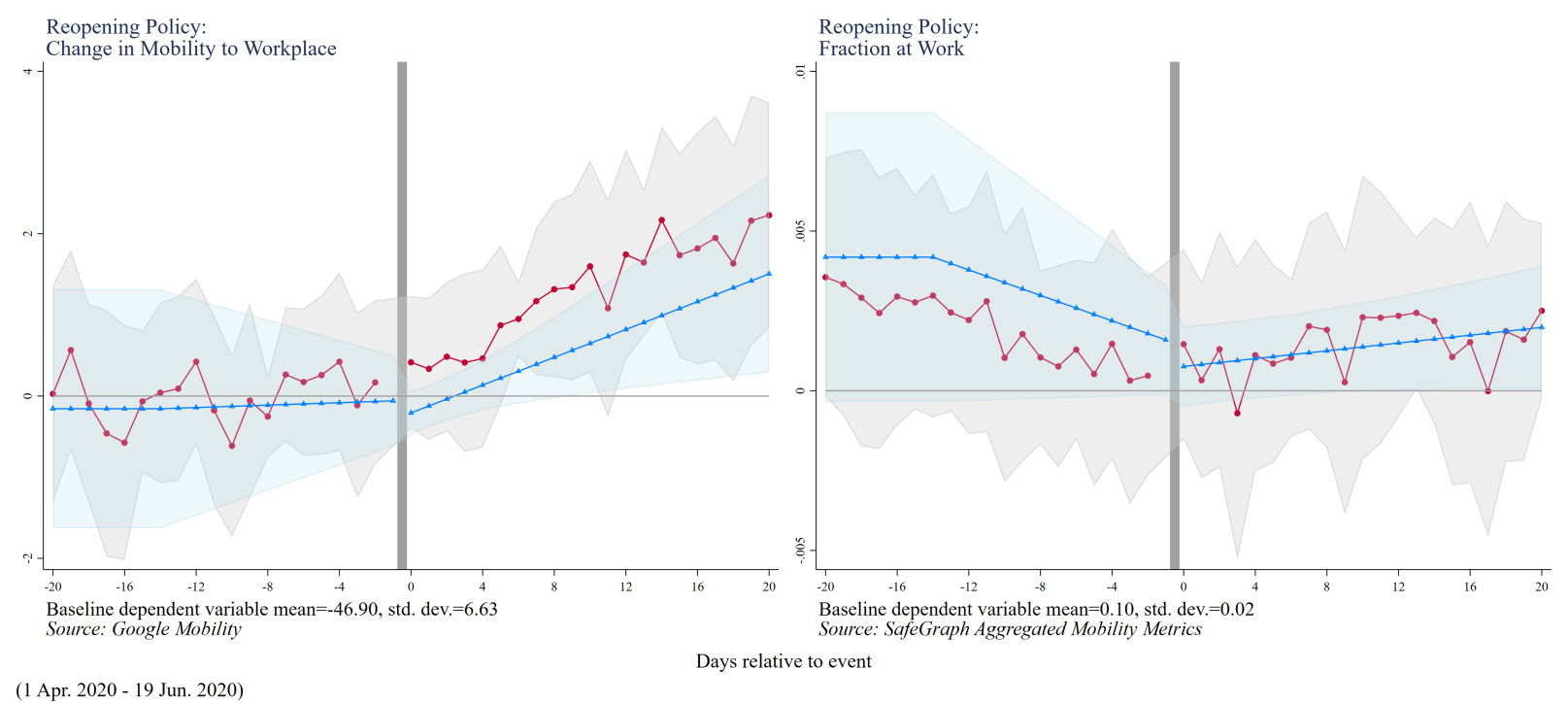

Notes: Authors' calculation based on cellular device movement data from Google Mobility and SafeGraph Aggregated Mobility Metrics. Both panels are from separate regressions. The vertical gray line denotes the day before the truncated re-opening announcement date in the state. The red series and grey shading are estimates from an event study with a set of dummy variables indicating each day. The blue series and shading are estimates from a linearized event study where linear time trends are imposed before and after policy change. The regressions control for state fixed effects and date fixed effects. The estimation sample window is 15 April 2020 - 05 June 2020. Reported baseline dependent variables as of 15 April 2020. 
Figure 7: Trends in job postings
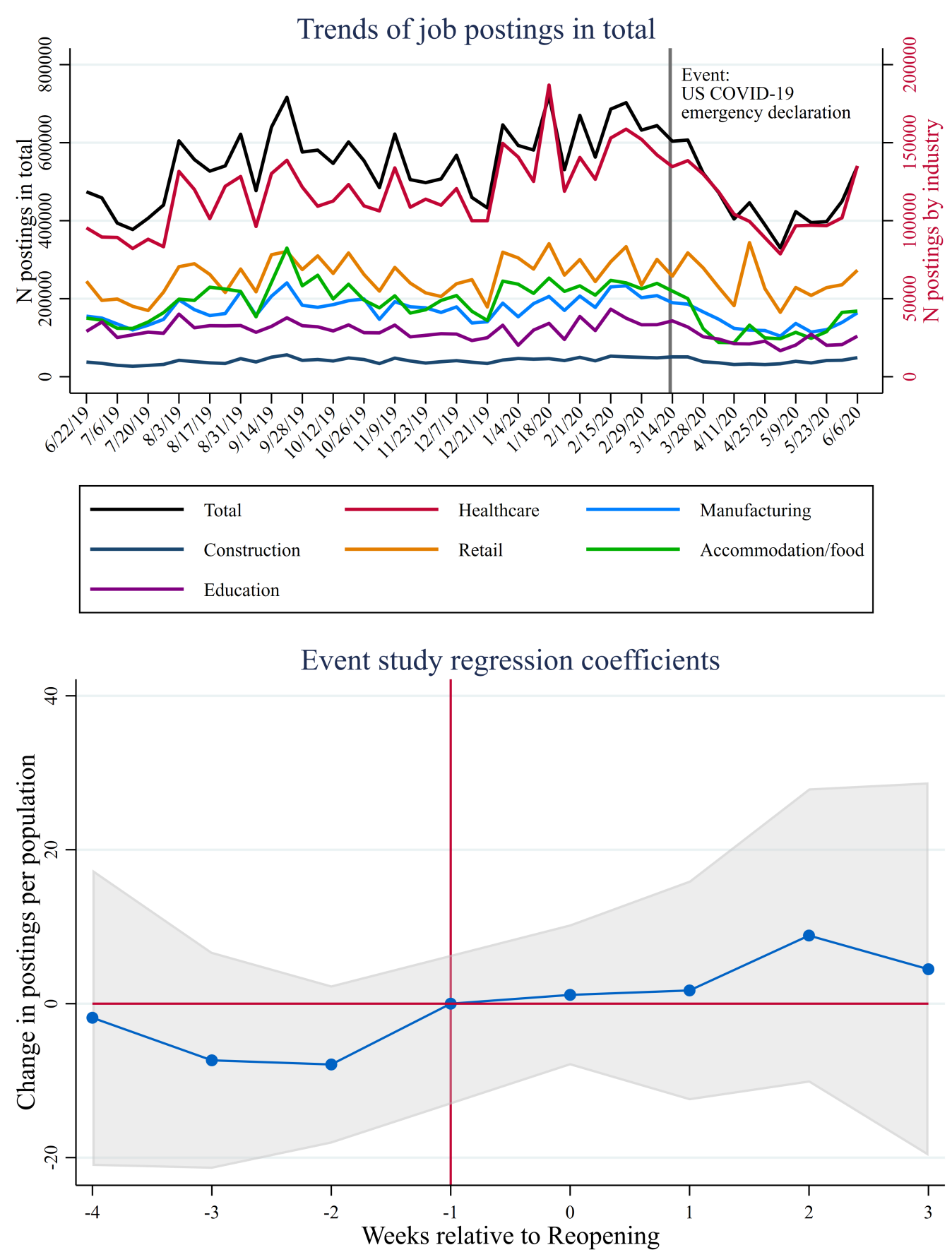

Notes: Authors' calculations based on Burning Glass Technology (BGT) job postings data. We are grateful to Burning Glass Technology for access to job postings data. The black series in the top panel shows trends in the total number of job postings by week (left axis). The other series provide estimates by sector. The bottom panel plots event study regression coefficients and 95 percent confidence intervals. The outcome is the weekly number of job postings per 100,000 state population. The sample window is April 11, 2020 - June 10, 2020. The vertical red line denotes the week before the truncated announcement date. The model includes state fixed effects and date fixed effects. Sta3tlard errors clustered at state level. 
Figure 8: Transition of Employment Status
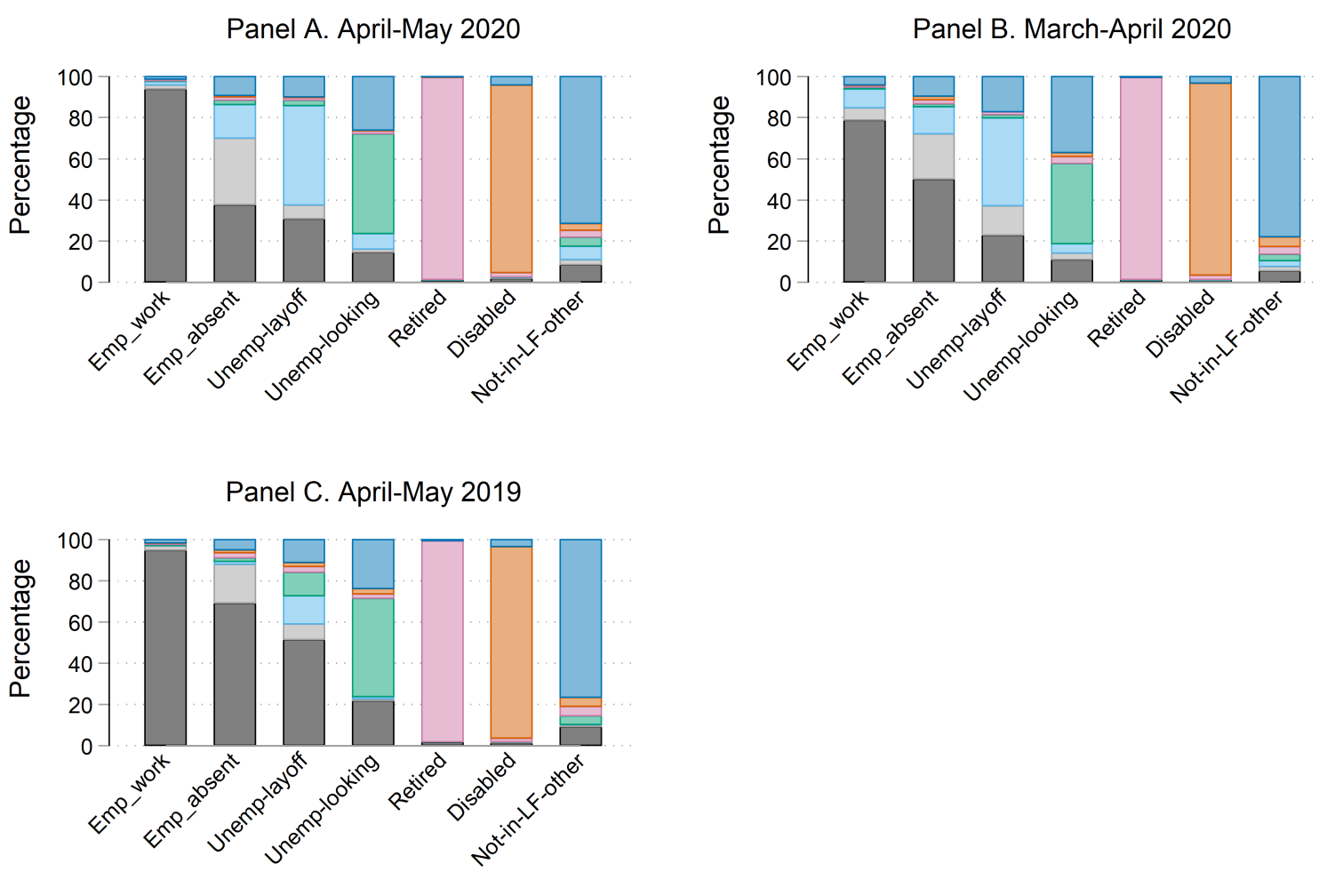

Emp_work

Emp_absent

Unemp-layoff

Unemp-looking

Retired

Disabled

Not-in-LF-other

Notes: Each graph shows the transition of matched CPS individuals from the previous month to the focal month. The horizontal axis represents employment status in the previous month and color of the bar represents employment status in the focal month. The focal months for the Panels A, B and C are May 2020, April 2020, and May 2019 respectively. 
Figure 9: Reemployment by previous employment status
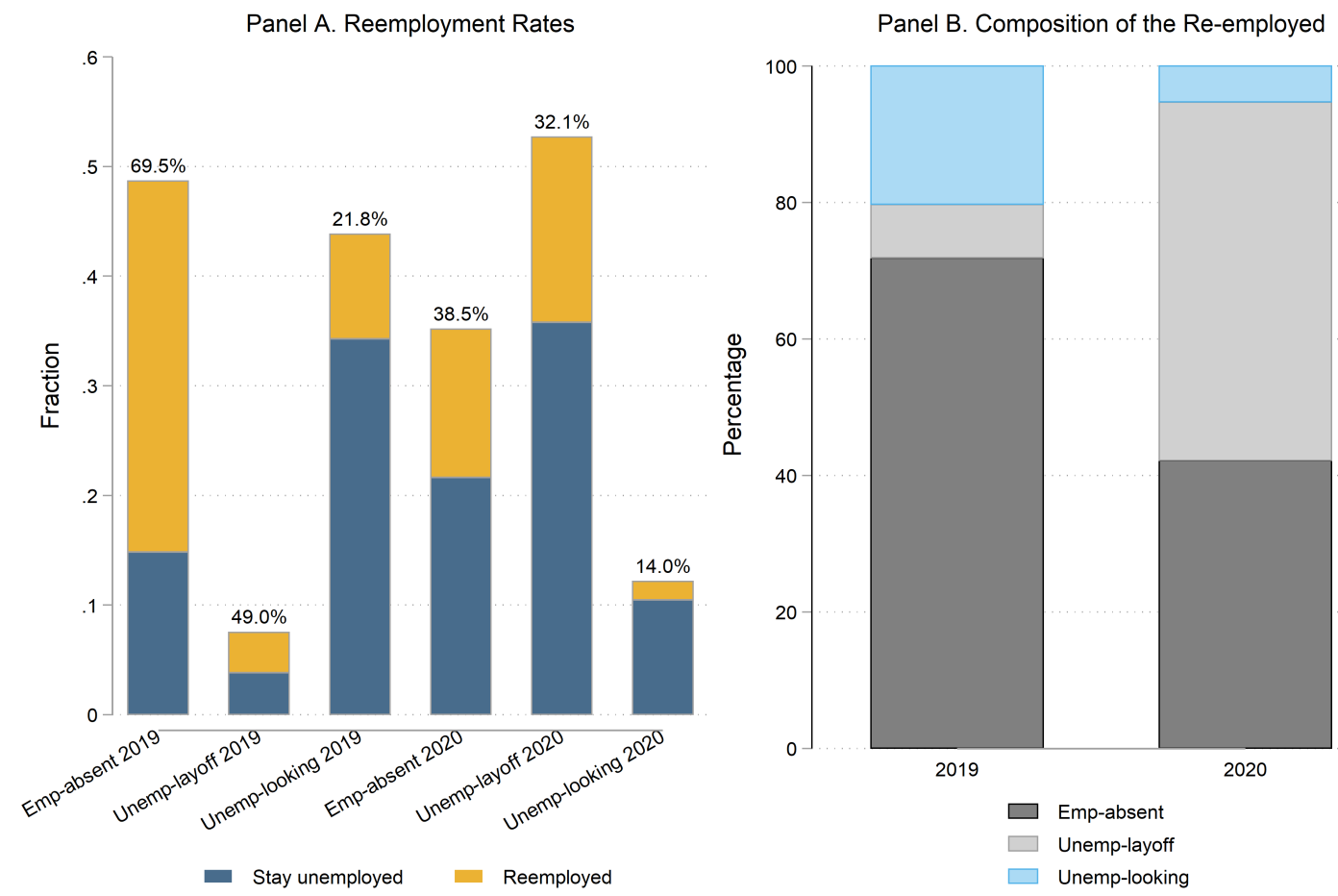

Notes: The sample includes not-working individuals (both the employed but absent and the unemployed) in April 2019 and 2020. Panel A shows the fraction of individuals belonging to each April employment status and the colors represent whether they are reemployed in May. The numbers on top of the bars indicate the reemployment probability for each group (i.e. the ratio of the yellow to the blue portions of the bars). Panel B shows the composition of the reemployed broken down by April employment status in 2019 and 2020 . 
Figure 10: Industry and Occupation Switches

(a) Industry

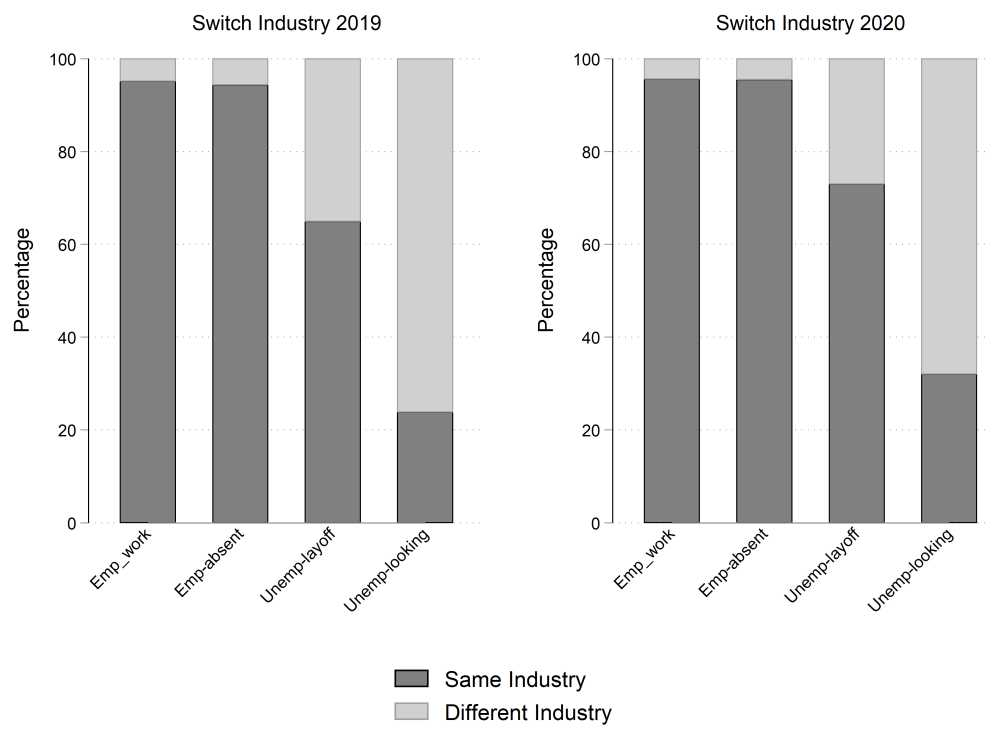

(b) Occupation

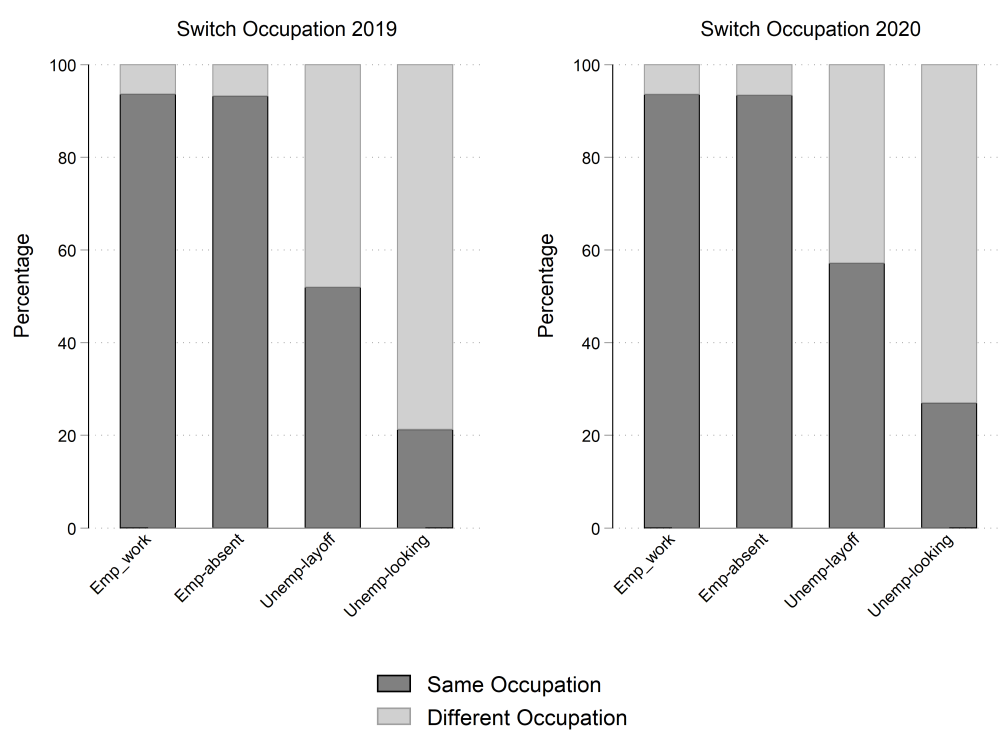

Notes: This figure depicts whether individuals switch industries or occupations in May conditional on being employed in May. Different bars represent different groups of people by their employment status in April. Panel (a) shows industry switches and Panel (b) shows occupation switches. The figure on the left of each panel represents 2019, and the right one represents 2020. An individual who has a different non-missing census occupation code in May from that in April is considered to have switched occupation. Industry switchers are defined similarly using census industry codes. 
Figure 11: Duration of Unemployment and Probability of Re-employment
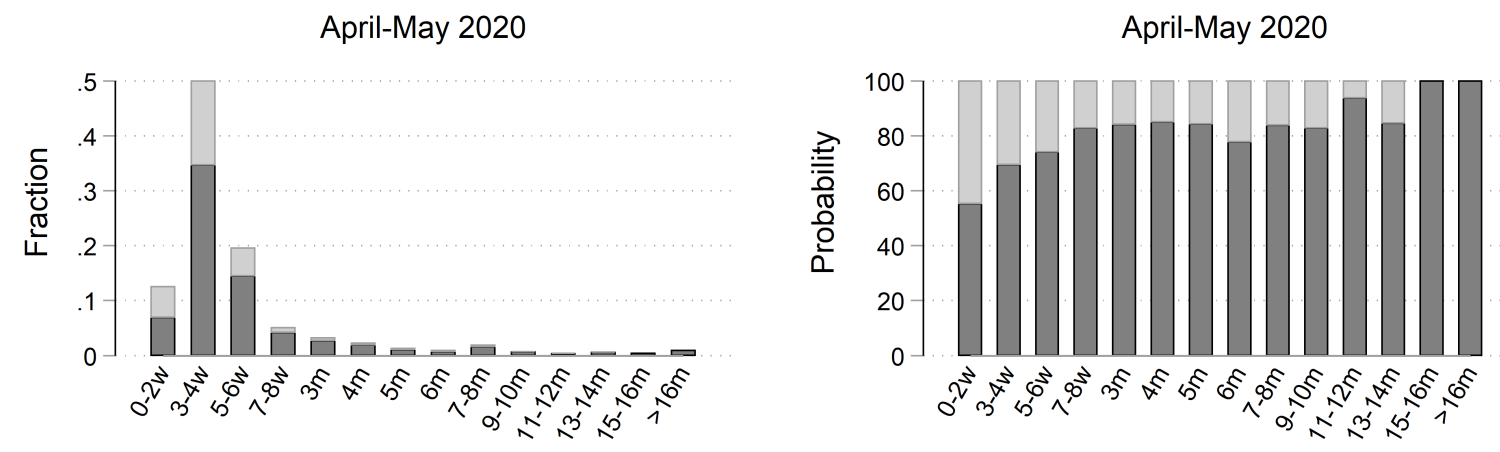

April-May 2019
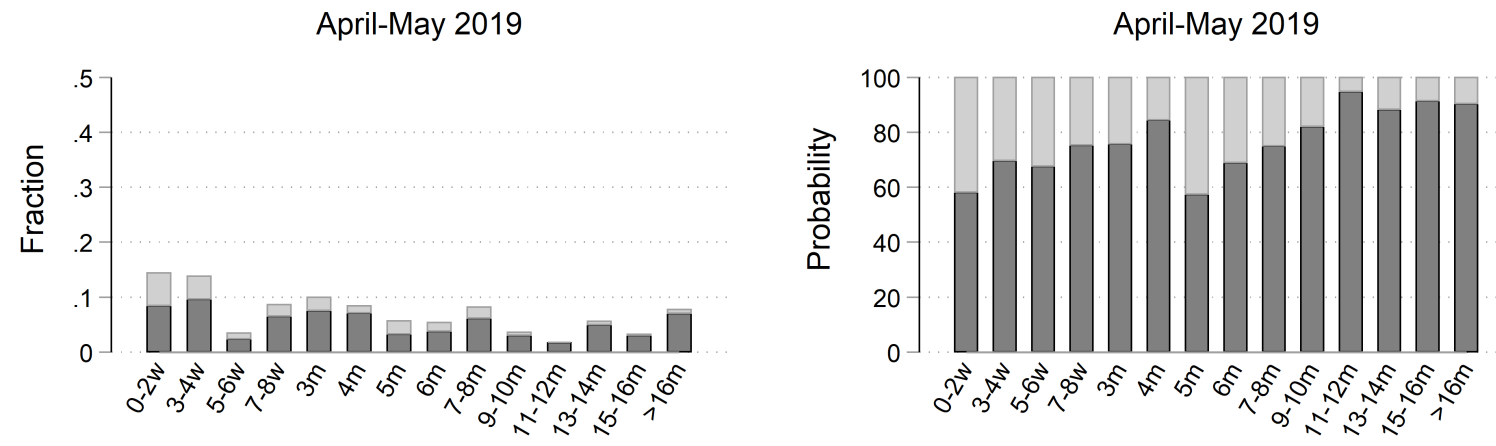

$\square$ Stay unemployed

\section{Re-employed}

Notes: The left panel presents the distribution of unemployment duration in April and the right panel shows the probability of reemployment in May by duration of unemployment. The sample comprises unemployed individuals, including those unemployed-on-layoff and unemployed-looking in April. The top panel presents results for 2020 and the bottom panel presents results for 2019 . 
Figure 12: Unemployment rate and Re-employment rate
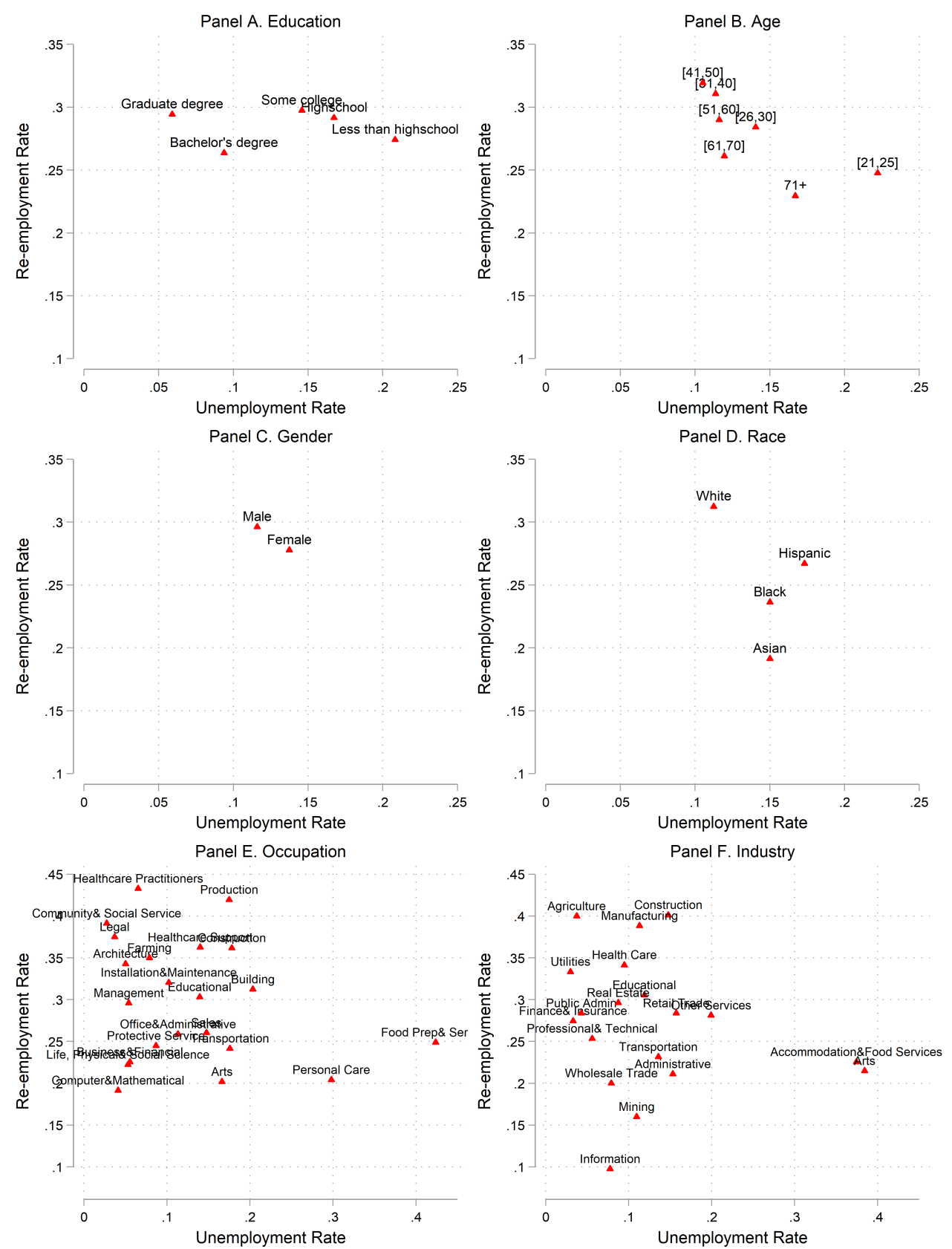

Notes: The figure presents the relationship between the unemployment rate (horizontal axis) and reemployment rate (vertical axis) for different education, age, gender and race groups, as well as different occupations and industries. The sample is the matched April-May 2020 CPS sample. 
Table 1: Effects of Reopening Policies on Labor Market Outcomes

\begin{tabular}{lcccccc}
\hline & $\begin{array}{c}(1) \\
\text { Empl. }\end{array}$ & $\begin{array}{c}(2) \\
\text { Empl. } \\
\text { Absent }\end{array}$ & $\begin{array}{c}(3) \\
\text { Earn - } \\
\text { Empl. }\end{array}$ & $\begin{array}{c}(4) \\
\text { Earn - } \\
\text { Overall }\end{array}$ & $\begin{array}{c}\text { Hrs Last Wk } \\
\text { - Empl. }\end{array}$ & $\begin{array}{c}(6) \\
\text { Hrs Last Wk } \\
\text { - Overall }\end{array}$ \\
\hline Days since Reopening x May & $\begin{array}{c}0.0022^{* *} \\
(0.0005)\end{array}$ & $\begin{array}{c}-0.0007^{* *} \\
(0.0002)\end{array}$ & $\begin{array}{c}-0.0013 \\
(0.0017)\end{array}$ & $\begin{array}{c}0.0106^{*} \\
(0.0062)\end{array}$ & $\begin{array}{c}-0.0215 \\
(0.0173)\end{array}$ & $\begin{array}{c}0.0540^{* *} \\
(0.0187)\end{array}$ \\
\hline Controls & $\mathrm{X}$ & $\mathrm{X}$ & $\mathrm{X}$ & $\mathrm{X}$ & $\mathrm{X}$ & $\mathrm{X}$ \\
\hline R-squared & 0.2697 & 0.0073 & 0.2275 & 0.3187 & 0.0707 & 0.2862 \\
N & $1,449,554$ & $1,449,554$ & 200,525 & 347,278 & 846,700 & $1,416,425$ \\
\hline Mean of D.V. (May) & 0.5157 & 0.0335 & 7.4984 & 3.8875 & 38.3383 & 20.4559 \\
Mean of D.V. (April) & 0.4897 & 0.0460 & 7.4823 & 3.7872 & 37.9826 & 19.4972 \\
Mean of D.V. (Full) & 0.5948 & 0.0230 & 7.4020 & 4.3784 & 39.3456 & 23.9556 \\
\hline
\end{tabular}

Notes: A * /** next to the coefficient indicates significance at the 10/5\% level. Sample includes 2019 January to 2020 May CPS data. Control variables are: Female, Has a child under 6, Female x Has a child under 6, Black, Hispanic, Age (21-25), Age (26-30), Age (31-40), Age (51-60), Age $(71+)$, Less than High School, Some College, Bachelor's degree, Graduate degree, and Metropolitan status. State fixed effects and year-month fixed effects are controlled for in all regressions. Standard errors are clustered at state level. The last three rows in the table show the mean values of the dependent variables for the full sample, 2020 April sample and 2020 May sample respectively. 
Table 2: Probability of Re-employment/Job Loss in May 2019 VS 2020

\begin{tabular}{|c|c|c|c|c|c|c|}
\hline & $\begin{array}{c}(1) \\
\text { Re-emp } \\
2019\end{array}$ & $\begin{array}{c}(2) \\
\text { Re-emp } \\
2020\end{array}$ & $\begin{array}{c}(3) \\
\text { Re-emp Diff. }\end{array}$ & $\begin{array}{c}(4) \\
\text { Loss Job } \\
2019\end{array}$ & $\begin{array}{c}(5) \\
\text { Loss Job } \\
2020\end{array}$ & $\begin{array}{c}(6) \\
\text { Loss Job } \\
\text { Diff. }\end{array}$ \\
\hline Days since Reopening & & $\begin{array}{c}0.0114^{* *} \\
(0.0023)\end{array}$ & $\begin{array}{c}0.0114^{* *} \\
(0.0023)\end{array}$ & & $\begin{array}{l}-0.0007 \\
(0.0005)\end{array}$ & $\begin{array}{l}-0.0007 \\
(0.0005)\end{array}$ \\
\hline Length SAH & & $\begin{array}{c}0.0018 \\
(0.0015)\end{array}$ & $\begin{array}{c}0.0018 \\
(0.0015)\end{array}$ & & $\begin{array}{l}-0.0003 \\
(0.0003)\end{array}$ & $\begin{array}{l}-0.0003 \\
(0.0003)\end{array}$ \\
\hline Employed-Absent & $\begin{array}{c}0.3983^{* *} \\
(0.0358)\end{array}$ & $\begin{array}{c}0.1740^{* *} \\
(0.0265)\end{array}$ & $\begin{array}{c}-0.2243^{* *} \\
(0.0459)\end{array}$ & & & \\
\hline Employed-On Layoff & $\begin{array}{c}0.2038^{* *} \\
(0.0465)\end{array}$ & $\begin{array}{c}0.1332^{* *} \\
(0.0288)\end{array}$ & $\begin{array}{l}-0.0706 \\
(0.0509)\end{array}$ & & & \\
\hline Unemployment Duration & $\begin{array}{c}-0.0019^{* *} \\
(0.0005)\end{array}$ & $\begin{array}{c}-0.0032^{* *} \\
(0.0005)\end{array}$ & $\begin{array}{c}-0.0013^{* *} \\
(0.0005)\end{array}$ & & & \\
\hline Essential & $\begin{array}{l}-0.0230 \\
(0.0334)\end{array}$ & $\begin{array}{c}0.0614^{* *} \\
(0.0238)\end{array}$ & $\begin{array}{l}0.0844^{*} \\
(0.0426)\end{array}$ & $\begin{array}{l}-0.0004 \\
(0.0042)\end{array}$ & $\begin{array}{l}-0.0091 \\
(0.0055)\end{array}$ & $\begin{array}{l}-0.0087 \\
(0.0078)\end{array}$ \\
\hline Face-to-Face & $\begin{array}{c}0.0264 \\
(0.0158)\end{array}$ & $\begin{array}{l}-0.0056 \\
(0.0092)\end{array}$ & $\begin{array}{l}-0.0320^{*} \\
(0.0174)\end{array}$ & $\begin{array}{l}-0.0001 \\
(0.0016)\end{array}$ & $\begin{array}{c}0.0099^{* *} \\
(0.0021)\end{array}$ & $\begin{array}{c}0.0100^{* *} \\
(0.0027)\end{array}$ \\
\hline Remote Work & $\begin{array}{c}0.0204 \\
(0.0265)\end{array}$ & $\begin{array}{c}0.0429 * * \\
(0.0135)\end{array}$ & $\begin{array}{c}0.0225 \\
(0.0335) \\
\end{array}$ & $\begin{array}{l}-0.0006 \\
(0.0027) \\
\end{array}$ & $\begin{array}{l}-0.0052 \\
(0.0031)\end{array}$ & $\begin{array}{l}-0.0046 \\
(0.0042) \\
\end{array}$ \\
\hline Has Child Under 6 & $\begin{array}{c}0.0404 \\
(0.0928)\end{array}$ & $\begin{array}{c}0.0041 \\
(0.0367)\end{array}$ & $\begin{array}{l}-0.0363 \\
(0.0724)\end{array}$ & $\begin{array}{c}0.0017 \\
(0.0039)\end{array}$ & $\begin{array}{l}-0.0027 \\
(0.0061)\end{array}$ & $\begin{array}{l}-0.0044 \\
(0.0085)\end{array}$ \\
\hline Female & $\begin{array}{c}0.0280 \\
(0.0307)\end{array}$ & $\begin{array}{l}-0.0268^{*} \\
(0.0147)\end{array}$ & $\begin{array}{l}-0.0548^{*} \\
(0.0311)\end{array}$ & $\begin{array}{c}0.0009 \\
(0.0019)\end{array}$ & $\begin{array}{l}0.0057^{*} \\
(0.0032)\end{array}$ & $\begin{array}{c}0.0048 \\
(0.0035)\end{array}$ \\
\hline Has Child Under $6 \times$ Female & $\begin{array}{c}-0.2879^{* *} \\
(0.0599)\end{array}$ & $\begin{array}{l}-0.1031^{*} \\
(0.0537)\end{array}$ & $\begin{array}{c}0.1848^{* *} \\
(0.0731)\end{array}$ & $\begin{array}{c}0.0076 \\
(0.0068)\end{array}$ & $\begin{array}{c}0.0237^{* *} \\
(0.0077)\end{array}$ & $\begin{array}{c}0.0161 \\
(0.0119)\end{array}$ \\
\hline Less than High School & $\begin{array}{l}-0.0502 \\
(0.0463)\end{array}$ & $\begin{array}{l}-0.0231 \\
(0.0320)\end{array}$ & $\begin{array}{c}0.0271 \\
(0.0472)\end{array}$ & $\begin{array}{c}0.0005 \\
(0.0042)\end{array}$ & $\begin{array}{l}-0.0007 \\
(0.0067)\end{array}$ & $\begin{array}{l}-0.0012 \\
(0.0080)\end{array}$ \\
\hline Some College & $\begin{array}{c}0.0439 \\
(0.0384)\end{array}$ & $\begin{array}{l}-0.0200 \\
(0.0127)\end{array}$ & $\begin{array}{l}-0.0639 \\
(0.0392)\end{array}$ & $\begin{array}{c}0.0050 \\
(0.0031)\end{array}$ & $\begin{array}{l}0.0118^{*} \\
(0.0059)\end{array}$ & $\begin{array}{c}0.0069 \\
(0.0051)\end{array}$ \\
\hline Bachelors Degree & $\begin{array}{l}-0.0112 \\
(0.0499)\end{array}$ & $\begin{array}{l}-0.0049 \\
(0.0185)\end{array}$ & $\begin{array}{c}0.0063 \\
(0.0511)\end{array}$ & $\begin{array}{c}0.0038 \\
(0.0032)\end{array}$ & $\begin{array}{l}-0.0057 \\
(0.0044)\end{array}$ & $\begin{array}{c}-0.0095^{*} \\
(0.0049)\end{array}$ \\
\hline Graduate Degree & $\begin{array}{c}0.0705 \\
(0.0520)\end{array}$ & $\begin{array}{c}0.0126 \\
(0.0410)\end{array}$ & $\begin{array}{l}-0.0579 \\
(0.0701)\end{array}$ & $\begin{array}{c}0.0006 \\
(0.0043)\end{array}$ & $\begin{array}{c}-0.0111^{* *} \\
(0.0055)\end{array}$ & $\begin{array}{c}-0.0117^{* *} \\
(0.0058)\end{array}$ \\
\hline Age (21-25) & $\begin{array}{c}-0.1010^{* *} \\
(0.0436)\end{array}$ & $\begin{array}{l}-0.0058 \\
(0.0315)\end{array}$ & $\begin{array}{c}0.0952 \\
(0.0596)\end{array}$ & $\begin{array}{l}-0.0018 \\
(0.0038)\end{array}$ & $\begin{array}{l}0.0197^{*} \\
(0.0105)\end{array}$ & $\begin{array}{c}0.0215^{* *} \\
(0.0100)\end{array}$ \\
\hline Age (26-30) & $\begin{array}{l}-0.0236 \\
(0.0431)\end{array}$ & $\begin{array}{l}-0.0004 \\
(0.0257)\end{array}$ & $\begin{array}{c}0.0232 \\
(0.0474)\end{array}$ & $\begin{array}{l}-0.0037 \\
(0.0046)\end{array}$ & $\begin{array}{c}0.0067 \\
(0.0044)\end{array}$ & $\begin{array}{l}0.0104^{*} \\
(0.0058)\end{array}$ \\
\hline Age (31-40) & $\begin{array}{l}-0.0424 \\
(0.0404)\end{array}$ & $\begin{array}{c}0.0334 \\
(0.0251)\end{array}$ & $\begin{array}{c}0.0758 \\
(0.0513)\end{array}$ & $\begin{array}{c}-0.0067^{* *} \\
(0.0026)\end{array}$ & $\begin{array}{l}-0.0031 \\
(0.0077)\end{array}$ & $\begin{array}{c}0.0036 \\
(0.0086)\end{array}$ \\
\hline Age (51-60) & $\begin{array}{c}-0.0904^{*} \\
(0.0453)\end{array}$ & $\begin{array}{l}-0.0093 \\
(0.0227)\end{array}$ & $\begin{array}{c}0.0811 \\
(0.0508)\end{array}$ & $\begin{array}{c}0.0023 \\
(0.0031)\end{array}$ & $\begin{array}{l}-0.0001 \\
(0.0049)\end{array}$ & $\begin{array}{l}-0.0024 \\
(0.0053)\end{array}$ \\
\hline Age (61-70) & $\begin{array}{c}-0.1166^{* *} \\
(0.0461)\end{array}$ & $\begin{array}{c}-0.0645^{* *} \\
(0.0276)\end{array}$ & $\begin{array}{c}0.0522 \\
(0.0567)\end{array}$ & $\begin{array}{c}0.0084^{* *} \\
(0.0031)\end{array}$ & $\begin{array}{c}0.0147^{* *} \\
(0.0072)\end{array}$ & $\begin{array}{c}0.0063 \\
(0.0078)\end{array}$ \\
\hline Age $(71+)$ & $\begin{array}{l}-0.0722 \\
(0.0785)\end{array}$ & $\begin{array}{l}-0.0432 \\
(0.0343)\end{array}$ & $\begin{array}{c}0.0290 \\
(0.0934)\end{array}$ & $\begin{array}{c}0.0178^{* *} \\
(0.0087)\end{array}$ & $\begin{array}{c}0.0283^{* *} \\
(0.0109)\end{array}$ & $\begin{array}{c}0.0105 \\
(0.0156)\end{array}$ \\
\hline Hispanic & $\begin{array}{c}0.0323 \\
(0.0257)\end{array}$ & $\begin{array}{l}-0.0016 \\
(0.0192)\end{array}$ & $\begin{array}{c}-0.0339 \\
(0.0332)\end{array}$ & $\begin{array}{c}0.0058 \\
(0.0037)\end{array}$ & $\begin{array}{c}0.0030 \\
(0.0082)\end{array}$ & $\begin{array}{c}-0.0028 \\
(0.0086)\end{array}$ \\
\hline African-American & $\begin{array}{c}-0.0660^{*} \\
(0.0373)\end{array}$ & $\begin{array}{l}-0.0408 \\
(0.0254)\end{array}$ & $\begin{array}{c}0.0252 \\
(0.0336)\end{array}$ & $\begin{array}{c}0.0019 \\
(0.0045)\end{array}$ & $\begin{array}{c}0.0190^{* *} \\
(0.0079)\end{array}$ & $\begin{array}{c}0.0171^{* *} \\
(0.0080)\end{array}$ \\
\hline Metropolitan & $\begin{array}{l}-0.0385 \\
(0.0378)\end{array}$ & $\begin{array}{c}0.0493^{* *} \\
(0.0239)\end{array}$ & $\begin{array}{l}0.0878^{*} \\
(0.0502)\end{array}$ & $\begin{array}{c}0.0047 \\
(0.0045)\end{array}$ & $\begin{array}{l}-0.0079 \\
(0.0051)\end{array}$ & $\begin{array}{c}-0.0126^{*} \\
(0.0065)\end{array}$ \\
\hline $\mathrm{N}$ & 6,975 & 6,975 & 6,975 & 48,827 & 48,827 & 48,827 \\
\hline$R^{2}$ & 0.1371 & 0.1371 & 0.1371 & 0.0150 & 0.0150 & 0.0150 \\
\hline
\end{tabular}

Notes: The sample consists of matched individuals from April to May in 2019 and 2020. The first three columns study factors affecting people's probability of re-employment in May conditional on being out of work in April. The last three columns study factors affecting people's likelihood of job loss in May conditional on being employed and at work in April. Re-employment means an individual transitions from not working (either unemployed or employed-absent) to employed and working; job loss means the opposite. Columns (1) and (4) report coefficients for 2019; Columns (2) and (5) report coefficients for 2020 and Columns (3) and (6) report the difference between the 2020 and 2019 coefficients. The length of Stay at Home (SAH) orders is calculated as number of days between enactment of SAH orders and the earlier of the expiration date of SAH orders, the reopening date, and May 12th. Other controls (not reported) include NAICS 2-digit industry dummies and their interaction with year, SOC 2-digit occupation dummies and their interactign with year. Longitudinal weights are incorporated in all regressions. Standard errors are cluster at state level. A*/** next to the coefficient indicates significance at the $10 / 5 \%$ level. 
Table 3: Earnings and Hours Worked conditional on (Re-)employed

\begin{tabular}{|c|c|c|c|c|c|c|}
\hline & $\begin{array}{c}(1) \\
\text { Earn2019 }\end{array}$ & $\begin{array}{c}(2) \\
\text { Earn2020 }\end{array}$ & $\begin{array}{c}(3) \\
\text { Earn Diff. }\end{array}$ & $\begin{array}{c}(4) \\
\text { Hours2019 }\end{array}$ & $\begin{array}{c}(5) \\
\text { Hours2020 }\end{array}$ & $\begin{array}{c}(6) \\
\text { Hours Diff. }\end{array}$ \\
\hline Days since Reopening & & $\begin{array}{l}-0.0001 \\
(0.0023)\end{array}$ & $\begin{array}{l}-0.0001 \\
(0.0023)\end{array}$ & & $\begin{array}{c}0.0643^{*} \\
(0.0332)\end{array}$ & $\begin{array}{l}0.0643^{*} \\
(0.0332)\end{array}$ \\
\hline Length SAH & & $\begin{array}{c}0.0008 \\
(0.0011)\end{array}$ & $\begin{array}{c}0.0008 \\
(0.0011)\end{array}$ & & $\begin{array}{c}0.0663^{* *} \\
(0.0221)\end{array}$ & $\begin{array}{c}0.0663^{* *} \\
(0.0221)\end{array}$ \\
\hline Employed-Work (prev.) & $\begin{array}{c}0.3300^{* *} \\
(0.1005)\end{array}$ & $\begin{array}{c}0.2120^{* *} \\
(0.0946)\end{array}$ & $\begin{array}{l}-0.1180 \\
(0.1468)\end{array}$ & $\begin{array}{l}3.5873^{*} \\
(2.0101)\end{array}$ & $\begin{array}{c}4.2076^{* *} \\
(1.9921)\end{array}$ & $\begin{array}{c}0.6203 \\
(1.9961)\end{array}$ \\
\hline Employed-Absent (prev.) & $\begin{array}{c}0.1832 \\
(0.1291)\end{array}$ & $\begin{array}{c}0.1147 \\
(0.1106)\end{array}$ & $\begin{array}{c}-0.0685 \\
(0.1786)\end{array}$ & $\begin{array}{c}0.7744 \\
(1.9991)\end{array}$ & $\begin{array}{c}-2.0576 \\
(1.8661)\end{array}$ & $\begin{array}{l}-2.8320 \\
(2.2002)\end{array}$ \\
\hline Employed-On Layoff (prev.) & $\begin{array}{c}0.1823 \\
(0.1918)\end{array}$ & $\begin{array}{c}0.0625 \\
(0.1031)\end{array}$ & $\begin{array}{l}-0.1197 \\
(0.2269)\end{array}$ & $\begin{array}{l}-3.6330 \\
(3.1334)\end{array}$ & $\begin{array}{l}-1.6839 \\
(1.6308)\end{array}$ & $\begin{array}{c}1.9492 \\
(3.3890)\end{array}$ \\
\hline Unemployment Duration (prev.) & $\begin{array}{l}-0.0007 \\
(0.0044)\end{array}$ & $\begin{array}{l}0.0062^{*} \\
(0.0035)\end{array}$ & $\begin{array}{c}0.0070 \\
(0.0057)\end{array}$ & $\begin{array}{c}-0.0928 \\
(0.0601)\end{array}$ & $\begin{array}{c}0.0427 \\
(0.1187)\end{array}$ & $\begin{array}{c}0.1355 \\
(0.1228)\end{array}$ \\
\hline Essential & $\begin{array}{c}0.0603^{* *} \\
(0.0195)\end{array}$ & $\begin{array}{c}0.0368^{*} \\
(0.0206)\end{array}$ & $\begin{array}{l}-0.0235 \\
(0.0272)\end{array}$ & $\begin{array}{c}0.7450^{* *} \\
(0.2687)\end{array}$ & $\begin{array}{c}0.4980 \\
(0.3438)\end{array}$ & $\begin{array}{l}-0.2470 \\
(0.5034)\end{array}$ \\
\hline Face-to-Face & $\begin{array}{c}-0.0354^{* *} \\
(0.0118)\end{array}$ & $\begin{array}{c}-0.0167 \\
(0.0118)\end{array}$ & $\begin{array}{c}0.0187 \\
(0.0167)\end{array}$ & $\begin{array}{c}0.3316^{* *} \\
(0.1401)\end{array}$ & $\begin{array}{c}0.4646^{* *} \\
(0.1472)\end{array}$ & $\begin{array}{c}0.1330 \\
(0.1885)\end{array}$ \\
\hline Remote Work & $\begin{array}{c}0.1236^{* *} \\
(0.0182) \\
\end{array}$ & $\begin{array}{c}0.1222^{* *} \\
(0.0137) \\
\end{array}$ & $\begin{array}{l}-0.0015 \\
(0.0174) \\
\end{array}$ & $\begin{array}{c}1.4853^{* *} \\
(0.1110)\end{array}$ & $\begin{array}{c}1.3822^{* * *} \\
(0.1522) \\
\end{array}$ & $\begin{array}{c}-0.1030 \\
(0.1722) \\
\end{array}$ \\
\hline Has Child Under 6 & $\begin{array}{c}0.0124 \\
(0.0289)\end{array}$ & $\begin{array}{l}-0.0022 \\
(0.0373)\end{array}$ & $\begin{array}{l}-0.0145 \\
(0.0311)\end{array}$ & $\begin{array}{c}0.2226 \\
(0.2606)\end{array}$ & $\begin{array}{c}0.3081 \\
(0.4887)\end{array}$ & $\begin{array}{c}0.0855 \\
(0.6281)\end{array}$ \\
\hline Female & $\begin{array}{c}-0.2576^{* *} \\
(0.0198)\end{array}$ & $\begin{array}{c}-0.2160^{* *} \\
(0.0222)\end{array}$ & $\begin{array}{c}0.0416 \\
(0.0343)\end{array}$ & $\begin{array}{c}-3.6362^{* *} \\
(0.2424)\end{array}$ & $\begin{array}{c}-2.5662^{* *} \\
(0.3233)\end{array}$ & $\begin{array}{l}1.0701^{* *} \\
(0.3329)\end{array}$ \\
\hline Has Child Under 6 x Female & $\begin{array}{c}0.0289 \\
(0.0471)\end{array}$ & $\begin{array}{c}0.0212 \\
(0.0632)\end{array}$ & $\begin{array}{l}-0.0077 \\
(0.0684)\end{array}$ & $\begin{array}{c}-1.9745^{* *} \\
(0.4510)\end{array}$ & $\begin{array}{c}-1.8761^{* *} \\
(0.4950)\end{array}$ & $\begin{array}{c}0.0984 \\
(0.7442)\end{array}$ \\
\hline Less than High School & $\begin{array}{c}-0.1380^{* *} \\
(0.0250)\end{array}$ & $\begin{array}{c}-0.2002^{\text {*** }} \\
(0.0306)\end{array}$ & $\begin{array}{c}-0.0622 \\
(0.0412)\end{array}$ & $\begin{array}{c}-0.7171^{* *} \\
(0.2625)\end{array}$ & $\begin{array}{c}-0.8195^{* *} \\
(0.3430)\end{array}$ & $\begin{array}{l}-0.1024 \\
(0.4052)\end{array}$ \\
\hline Some College & $\begin{array}{c}0.0280 \\
(0.0179)\end{array}$ & $\begin{array}{c}0.0138 \\
(0.0230)\end{array}$ & $\begin{array}{c}-0.0142 \\
(0.0289)\end{array}$ & $\begin{array}{c}0.0389 \\
(0.2306)\end{array}$ & $\begin{array}{c}0.0914 \\
(0.2831)\end{array}$ & $\begin{array}{c}0.0525 \\
(0.3615)\end{array}$ \\
\hline Bachelors Degree & $\begin{array}{c}0.2152^{* *} \\
(0.0265)\end{array}$ & $\begin{array}{c}0.2696^{* *} \\
(0.0211)\end{array}$ & $\begin{array}{c}0.0544^{* *} \\
(0.0206)\end{array}$ & $\begin{array}{c}0.4564 \\
(0.3221)\end{array}$ & $\begin{array}{c}0.4364 \\
(0.3439)\end{array}$ & $\begin{array}{l}-0.0200 \\
(0.4020)\end{array}$ \\
\hline Graduate Degree & $\begin{array}{c}0.3846^{* *} \\
(0.0305)\end{array}$ & $\begin{array}{c}0.4160^{* *} \\
(0.0307)\end{array}$ & $\begin{array}{c}0.0314 \\
(0.0389)\end{array}$ & $\begin{array}{c}1.0213^{* *} \\
(0.3342)\end{array}$ & $\begin{array}{c}1.5308^{* *} * \\
(0.4357)\end{array}$ & $\begin{array}{c}0.5095 \\
(0.3888)\end{array}$ \\
\hline Age (21-25) & $\begin{array}{c}-0.3738^{* *} \\
(0.0270)\end{array}$ & $\begin{array}{c}-0.4093^{* *} \\
(0.0318)\end{array}$ & $\begin{array}{l}-0.0355 \\
(0.0324)\end{array}$ & $\begin{array}{c}-3.0109 * * \\
(0.3585)\end{array}$ & $\begin{array}{c}-2.4077^{* *} \\
(0.3229)\end{array}$ & $\begin{array}{c}0.6032 \\
(0.3888)\end{array}$ \\
\hline Age (26-30) & $\begin{array}{c}-0.1685^{* *} \\
(0.0281)\end{array}$ & $\begin{array}{c}-0.2352^{* *} \\
(0.0263)\end{array}$ & $\begin{array}{c}-0.0667^{*} \\
(0.0355)\end{array}$ & $\begin{array}{l}-0.3140 \\
(0.3071)\end{array}$ & $\begin{array}{c}-1.0374^{* *} \\
(0.3319)\end{array}$ & $\begin{array}{c}-0.7234 \\
(0.4889)\end{array}$ \\
\hline Age (31-40) & $\begin{array}{c}-0.0850^{* *} \\
(0.0203)\end{array}$ & $\begin{array}{c}-0.0951^{* *} * \\
(0.0302)\end{array}$ & $\begin{array}{c}-0.0101 \\
(0.0362)\end{array}$ & $\begin{array}{c}-0.0927 \\
(0.2043)\end{array}$ & $\begin{array}{c}-0.0645 \\
(0.2481)\end{array}$ & $\begin{array}{c}0.0282 \\
(0.3297)\end{array}$ \\
\hline Age (51-60) & $\begin{array}{c}0.0483^{* *} \\
(0.0202)\end{array}$ & $\begin{array}{c}-0.0031 \\
(0.0219)\end{array}$ & $\begin{array}{c}-0.0514^{*} \\
(0.0286)\end{array}$ & $\begin{array}{c}-0.3324 \\
(0.2234)\end{array}$ & $\begin{array}{c}-0.5155 \\
(0.3238)\end{array}$ & $\begin{array}{l}-0.1832 \\
(0.3834)\end{array}$ \\
\hline Age (61-70) & $\begin{array}{c}-0.1561^{* *} \\
(0.0409)\end{array}$ & $\begin{array}{c}-0.1527^{* *} \\
(0.0326)\end{array}$ & $\begin{array}{c}0.0035 \\
(0.0461)\end{array}$ & $\begin{array}{c}-3.2951^{* *} \\
(0.2903)\end{array}$ & $\begin{array}{c}-2.8589^{* *} \\
(0.2980)\end{array}$ & $\begin{array}{c}0.4362 \\
(0.3468)\end{array}$ \\
\hline Age $(71+)$ & $\begin{array}{c}-0.4643^{* *} \\
(0.0883)\end{array}$ & $\begin{array}{c}-0.4202^{* *} \\
(0.0849)\end{array}$ & $\begin{array}{c}0.0441 \\
(0.1226)\end{array}$ & $\begin{array}{c}-9.4762^{* *} \\
(0.7980)\end{array}$ & $\begin{array}{c}-8.5478^{* *} \\
(0.7088)\end{array}$ & $\begin{array}{c}0.9284 \\
(0.6743)\end{array}$ \\
\hline Hispanic & $\begin{array}{c}-0.0512^{* *} \\
(0.0228)\end{array}$ & $\begin{array}{c}-0.0594^{* *} \\
(0.0184)\end{array}$ & $\begin{array}{c}-0.0083 \\
(0.0262)\end{array}$ & $\begin{array}{c}0.1381 \\
(0.3039)\end{array}$ & $\begin{array}{c}-0.1178 \\
(0.3805)\end{array}$ & $\begin{array}{c}-0.2559 \\
(0.2292)\end{array}$ \\
\hline African-American & $\begin{array}{c}-0.0625^{*} \\
(0.0313)\end{array}$ & $\begin{array}{c}-0.1274^{* *} \\
(0.0308)\end{array}$ & $\begin{array}{c}-0.0649^{*} \\
(0.0375)\end{array}$ & $\begin{array}{c}0.1095 \\
(0.2025)\end{array}$ & $\begin{array}{c}0.4960^{*} \\
(0.2860)\end{array}$ & $\begin{array}{c}0.3865 \\
(0.3298)\end{array}$ \\
\hline Metropolitan & $\begin{array}{c}-0.0665^{* *} \\
(0.0191) \\
\end{array}$ & $\begin{array}{c}-0.0966^{* *} \\
(0.0295) \\
\end{array}$ & $\begin{array}{c}-0.0301 \\
(0.0332) \\
\end{array}$ & $\begin{array}{l}0.6282^{*} \\
(0.3339) \\
\end{array}$ & $\begin{array}{c}0.1595 \\
(0.3229) \\
\end{array}$ & $\begin{array}{l}-0.4687 \\
(0.4288) \\
\end{array}$ \\
\hline $\mathrm{N}$ & 15,785 & 15,785 & 15,785 & 48,546 & 48,546 & 48,546 \\
\hline$R^{2}$ & 0.3499 & 0.3499 & 0.3499 & 0.1254 & 0.1254 & 0.1254 \\
\hline
\end{tabular}

The sample consists of people who are employed and at work in May 2019/2020. Columns (1)-(3) report results for earnings and Column (4)-(6) report results for hours worked last week. The reference group for previous employment status is 'unemployed-looking'. Columns (1) and (4) report coefficients for 2019; Columns (2) and (5) report coefficients for 2020 and Columns (3) and (6) report the difference between the 2020 and 2019 coefficients. The length of stay at home (SAH) orders is calculated as number of days between enactment of SAH orders and the earlier of expiration date of the SAH orders, the reopen date, and May 12th. Other control variables (not reported) include NAICS 2-digit industry dummies and their interaction with year, SOC 2-digit occupation dummies and their interaction with year. Longitudinal weights are incorporated in all regressions. Standard errors are clustered at state level. A * $/ * *$ next to the coefficient indicates significance at the $10 / 5 \%$ level. 


\section{A Appendix}

Figure 13: Estimated Coefficients for Industries

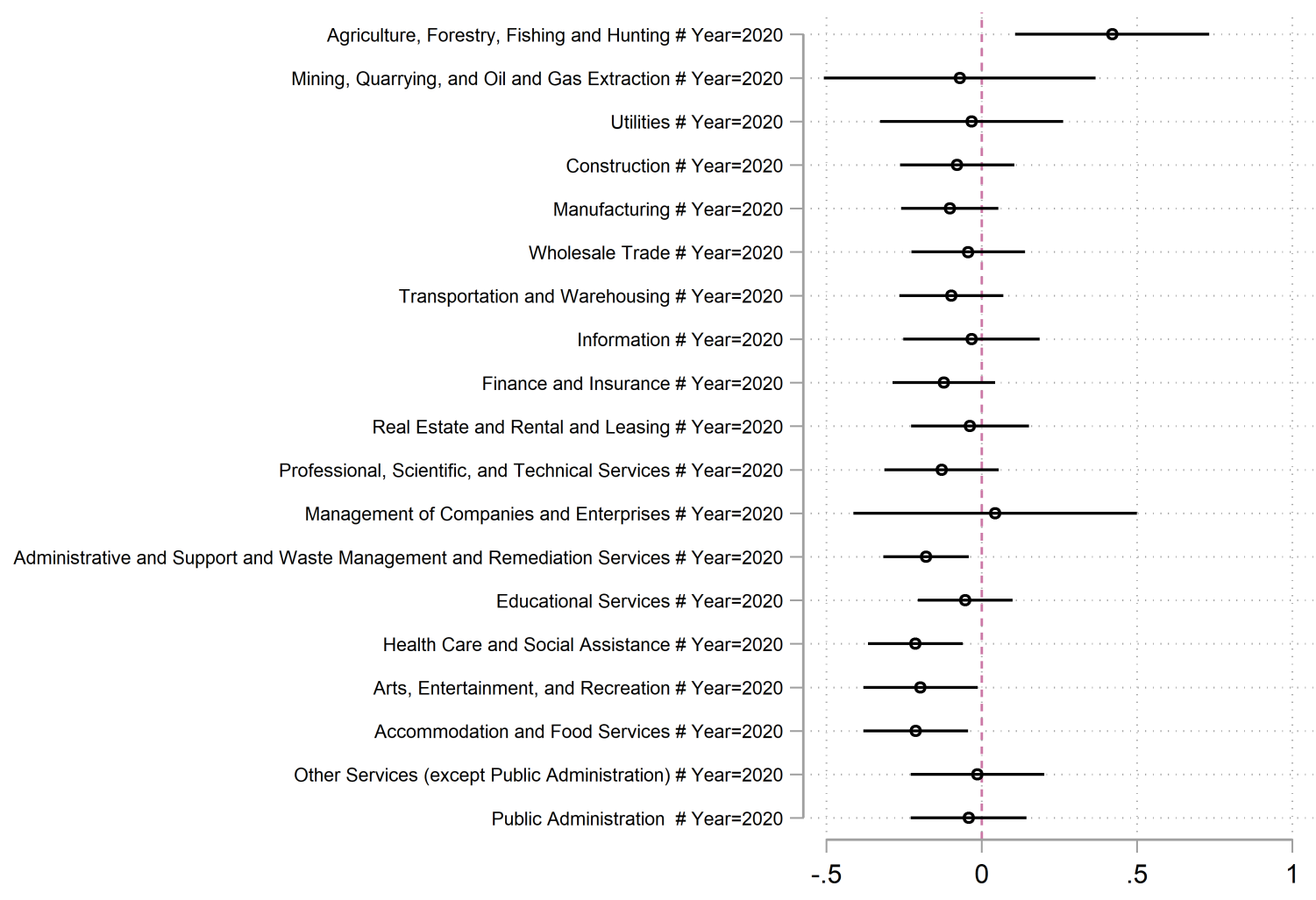

Notes: This figure plots 2020 differential effects for each industry (compared with 2019). The estimates are based on the regression in Table 2. In addition to the coefficients in front of industries interacted with year of 2020 terms (as plotted in the figure), the regression also has a full set of industry dummies which represents industry fixed effects in 2019. The reference industry is 'Retail Trade'. 
Figure 14: Estimated Coefficients for Occupations

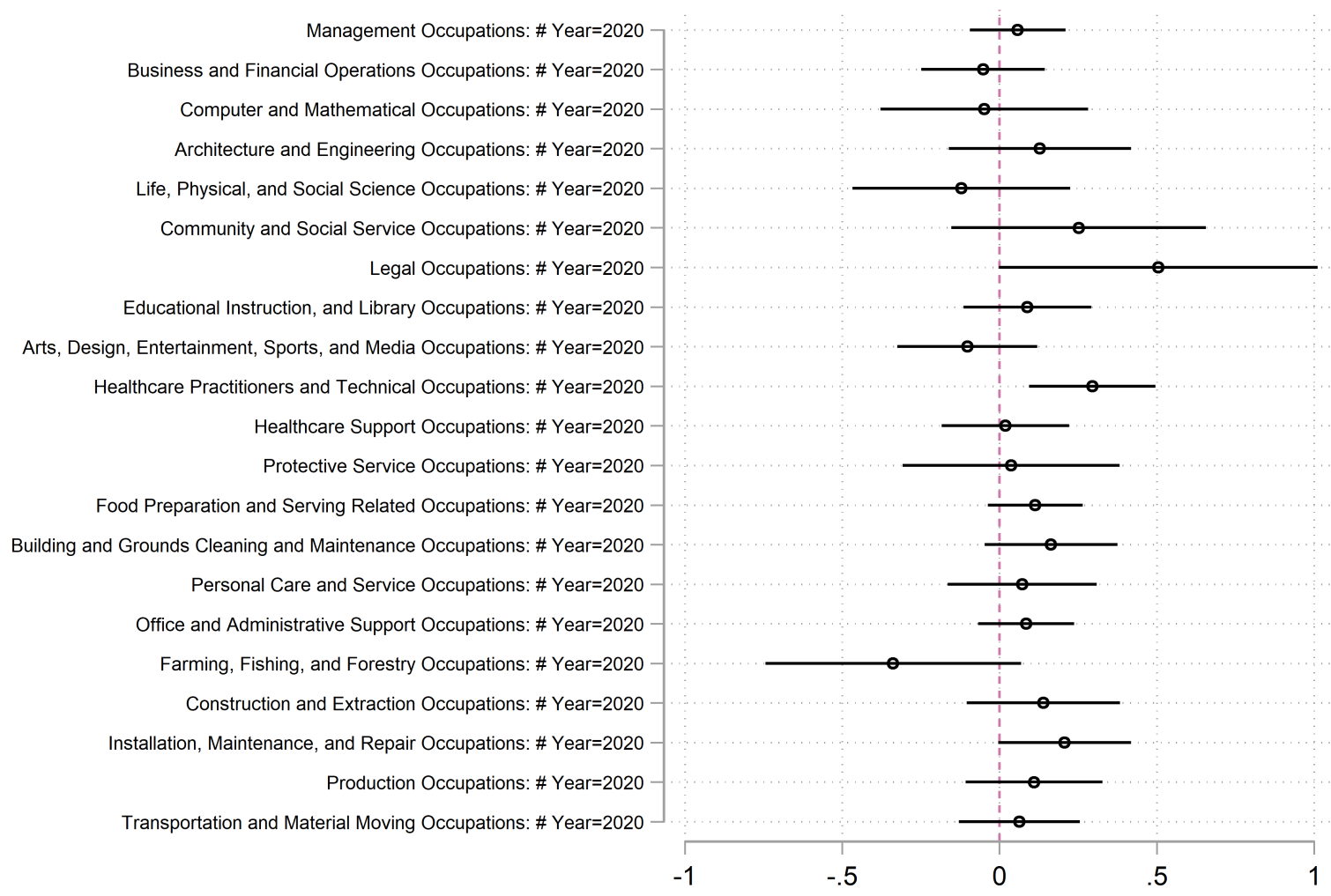

Notes: This figure plots 2020 differential effects for each occupation (compared with 2019). The estimates are based on the regression in Table 2 . In addition to the coefficients in front of occupations interacted with year of 2020 terms (as plotted in the figure), the regression also has a full set of occupations dummies which represents occupation fixed effects in 2019. The reference occupation is 'Sales and Related Occupations'. 


\section{References}

Aaronson, D., S. A. Brave, R. A. Butters, and M. Fogarty (2020). The stay-at-home labor market: Google searches, unemployment insurance, and public health orders. Technical report, Chicago Fed Letter, No. 436.

Adams-Prassl, A., T. Boneva, M. Golin, and C. Rauh (2020). Inequality in the impact of the coronavirus shock: New survey evidence for the uk. Cambridge-INET Working Paper Series (2020/09).

Alon, T. M., M. Doepke, J. Olmstead-Rumsey, and M. Tertilt (2020). The impact of covid-19 on gender equality. Technical report, National Bureau of Economic Research.

Anderson, P. M. and B. D. Meyer (2000). The effects of the unemployment insurance payroll tax on wages, employment, claims and denials. Journal of public Economics 78(1-2), $81-106$.

Baek, C., P. B. McCrory, T. Messer, and P. Mui (2020). Unemployment effects of stay-at-home orders: Evidence from high frequency claims data. Technical report, IRLE Working Paper $101-20$.

Bennedsen, M., B. Larsen, I. Schmutte, and D. Scur (2020). Preserving job matches during the covid-19 pandemic: Firm-level evidence on the role of government aid. Working paper, Cornell University.

Blau, F. D., J. Koebe, and P. A. Meyerhofer (2020, April). Essential and frontline workers in the covid-19 crisis. Econofact.

Blick, A. and A. Blandin (2020). Real-time labor market estimates during the 2020 coronavirus outbreak. Technical report, Arizona State University. 
Bogage, J. (2020, April). Coronavirus unemployment guide: What to do if you get laid off or furloughed. The Washington Post.

Borden, T. (2020, April). The coronavirus outbreak has triggered unprecedented mass layoffs and furloughs. Business Insider.

Cajner, T., L. D. Crane, R. A. Decker, A. Hamins-Puertolas, and C. Kurz (2020). Tracking labor market developments during the covid-19 pandemic: A preliminary assessment. Technical report, Finance and Economics Discussion Series 2020-030. Washington: Board of Governors of the Federal Reserve System, https://doi.org/10.17016/FEDS.2020.030.

Cajner, T., T. Radler, D. Ratner, and I. Vidangos (2017). Racial gaps in labor market outcomes in the last four decades and over the business cycle. Technical report, Finance and Economics Discussion Series 2017-071, Washington: Board of Governors of the Federal Reserve System, https://doi.org/10.17016/FEDS.2017.071.

Campello, M., G. Kankanhalli, and P. Muthukrishnan (2020). Tracking labor market developments during the covid-19 pandemic: A preliminary assessment. Technical report, National Bureau of Economic Research Working Paper 27208, DOI: 10.3386/w27208.

Chetty, R., J. Friedman, N. Hendren, and M. Stepner (2020). How did covid-19 and stabilization policies affect spending and employment? a new real-time economic tracker based on private sector data. Working paper, Opportunity Insights.

Choi, H. and H. Varian (2012). Predicting the present with google trends. Economic record 88, 2-9.

Coibin, O., Y. Gorodnichenko, and M. Weber (2020). The cost of the covid-19 epidemic: Lockdowns, macroeconomic expectations, and consumer spending. Technical report, University of Texas. 
Coibion, O., Y. Gorodnichenko, and M. Weber (2020, April). Labor markets during the COVID-19 Crisis: A preliminary view. Technical Report w27017, National Bureau of Economic Research, Cambridge, MA.

Dasgupta, K. and S. Murali (2020). Pandemic containment and inequality in a developing economy.

Davis, S. J. and T. von Wachter (2011). Recessions and the costs of job loss. Brookings Papers on Economic Activity, 1-72.

Deming, D. and L. B. Kahn (2018). Skill requirements across firms and labor markets: Evidence from job postings for professionals. Journal of Labor Economics 36(S1), S337S369.

Dingel, J. I. and B. Neiman (2020). How many jobs can be done at home? Technical report, National Bureau of Economic Research.

Fairlie, W. R. (2020). The impact of covid-19 on small business owners: Evidence of earlystage losses from the april 2020 current population survey. Technical report, National Bureau of Economic Research.

Fairlie, W. R., K. Couch, and H. Xu (2020). The impacts of covid-19 on minority unemployment: First evidence from april 2020 cps microdata. Technical report, National Bureau of Economic Research.

Farber, H. S. (2017). Employment, Hours, and Earnings Consequences of Job Loss: US Evidence from the Displaced Workers Survey. Journal of Labor Economics 35(S1), 235-272.

Friebel, G., M. Heinz, M. Hoffman, and N. Zubanov (2019, June). What do employee referral programs do? a firm-level randomized controlled trial. Working Paper 25920, National Bureau of Economic Research. 
Fullman, N., B. Bang-Jensen, K. Amano, C. Adolph, and J. Wilkerson (2020). State-level social distancing policies in response to COVID-19 in the US [Data file].

Gupta, S., T. D. Nguyen, F. Lozano-Rojas, S. Raman, B. Lee, A. Bento, K. I. Simon, and C. Wing (2020). Tracking public and private response to the covid-19 epidemic: Evidence from state and local government actions. Technical report, National Bureau of Economic Research.

Jacobson, L. S., R. J. LaLonde, and D. G. Sullivan (1993, September). Earnings Losses of Displaced Workers. American Economic Review 83(4), 685-709.

Jäger, S. and J. Heining (2016). How substitutable are workers? evidence from worker deaths. Working Paper.

Kahn, L. B., F. Lange, and D. G. Wiczer (2020). Labor demand in the time of covid-19: Evidence from vacancy postings and UI claims. Technical report, National Bureau of Economic Research.

Lachowska, M., A. Mas, and S. A. Woodbury (2018, January). Sources of displaced workers' long-term earnings losses. Working Paper 24217, National Bureau of Economic Research.

Leibovici, F., A. M. Santacreu, and M. Famiglietti (2020). Social distancing and contactintensive occupations. On the economy, St. Louis FED.

Lise, J. and J.-M. Robin (2017, April). The macrodynamics of sorting between workers and firms. American Economic Review 107(4), 1104-35.

Lozano-Rojas, F., X. Jiang, L. Montenovo, K. I. Simon, B. A. Weinberg, and C. Wing (2020). Is the cure worse than the problem itself? immediate labor market effects of covid-19 case rates and school closures in the us. Working Paper, National Bureau of Economic Research. 
Mongey, S. and A. Weinberg (2020). Characteristics of workers in low work-from-home and high personal-proximity occupations. Becker Friedman Institute for Economic White Paper.

Montenovo, L., X. Jiang, F. Lozano-Rojas, I. M. Schmutte, K. I. Simon, B. A. Weinberg, and C. Wing (2020). Determinants of disparities in covid-19 job losses. Technical report, National Bureau of Economic Research.

NCSL (2020). COVID-19: Unemployment Benefits. https://www.ncsl.org/research/ labor-and-employment/covid-19-unemployment-benefits.aspx.

Nguyen, T. D., S. Gupta, M. Andersen, A. Bento, K. I. Simon, and C. Wing (2020). Impacts of state reopening policy on human mobility. Technical report, National Bureau of Economic Research.

O*NET National Center for O*NET Development (2020). O*net online help: Data collection information. Data retrieved from O*NET Online on May 6, 2020 from www.onet.org.

Raifman, J., K. Nocka, D. Jones, J. Bor, S. Lipson, J. Jay, and P. Chan (2020). COVID-19 US state policy database. www.tinyurl.com/statepolicies.

Rothwell, J. and H. Van Drie (2020). The effect of covid-19 and disease suppression policies on labor markets: A preliminary analysis of the data. Data retrieved on May 24, 2020 from wwww.brookings.edu.

Schanzenbach, W. D., R. Nunn, L. Bauer, and A. Breitwieser (2017). The closing of the jobs gap - a decade of recession and recovery. Technical report, The Hamilton Project, Brookings.

Scrivner, O., T. Nguyen, K. Simon, E. Middaugh, B. Taska, and K. Börner (2020). Job postings in the substance use disorder treatment related sector during the first five years of medicaid expansion. PloS one 15(1), e0228394. 
Shumsky, T. and K. Broughton (2020, July). Companies choose furloughs over layoffs to manage coronavirus slowdown. Wall Street Journal.

U.S. Bureau of Labor Statistics (2020a, May). Employment situation summary. News Release USDL-20-1140, U.S. Bureau of Labor Statistics.

U.S. Bureau of Labor Statistics (2020b). Frequently asked questions: The impact of the coronavirus (covid-19) pandemic on the employment situation for april 2020. Document retrieved on May 6, 2020 from www.bls.gov.

U.S. Bureau of Labor Statistics (2020c). Frequently asked questions: The impact of the coronavirus (covid-19) pandemic on the employment situation for march 2020. Document retrieved on May 6, 2020 from www.bls.gov.

U.S. Bureau of Labor Statistics (2020d). Frequently asked questions: The impact of the coronavirus (covid-19) pandemic on the employment situation for may 2020. Document retrieved on June 12, 2020 from .

U.S. Census Bureau (2019, October). Current population survey: Design and methodology, technical paper 77. Technical report.

Vroman, W., E. Maag, C. J. O'Leary, and S. A. Woodbury (2017). A comparative analysis of unemployment insurance financing methods. 